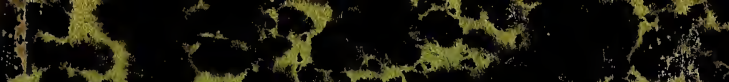

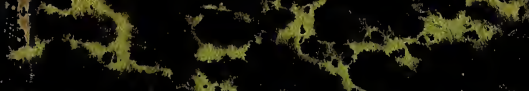

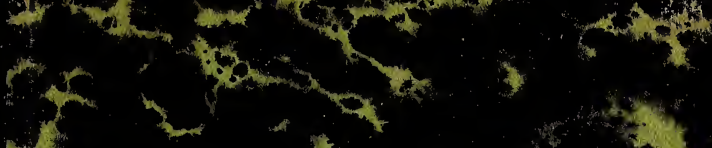

$+1$

\&

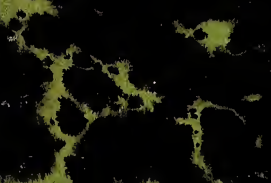

$3+5-x$

$1+x^{2}+x^{2}$

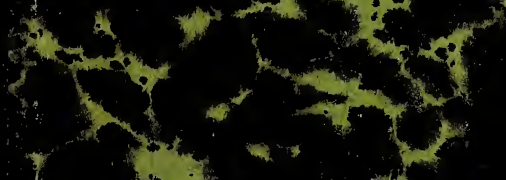

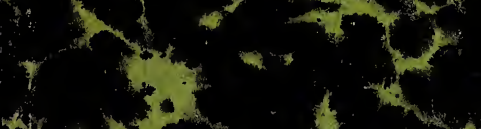

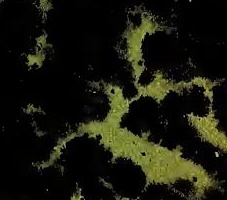
Bv $-x+4$
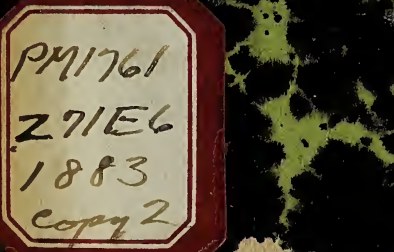

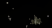
$(x+2$ $-2$ 8 as
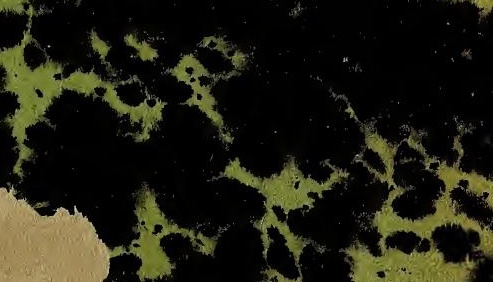
$$
\text { An. }
$$

$P^{3}+3 \pi^{3 k^{2}}$

lyw 
Kang. 




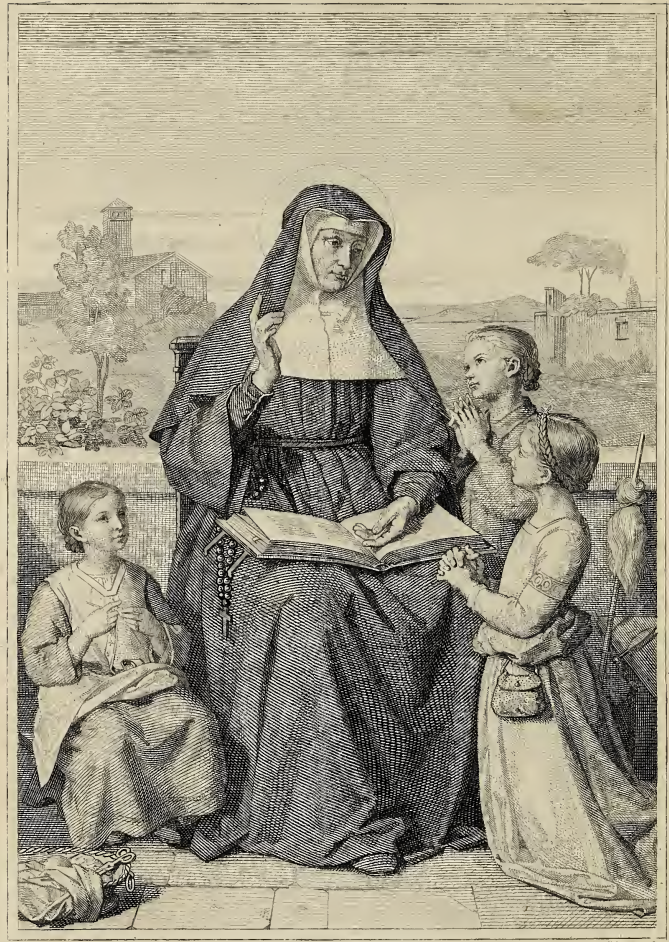

Tarrenstein invt.

Eitel 1e.

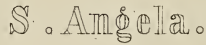

High enthum des Vereins zur Verbreitunó religh Bilder in liưffeldorf. Seul Dépôt à Paris chez AW. Schulgenen Editeur., 25, me St Sulpice. 


\section{KATOLIK ANAMIHAN,}

ene $k \ddot{a}$ :

JESUS OT ÄSECHZEKON

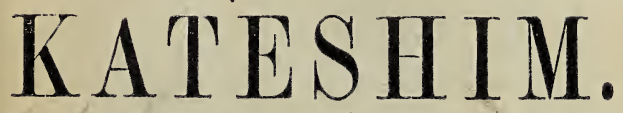

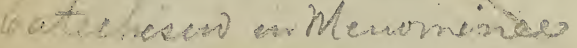

as wechzekatek.
Éngelhardt

F ZEPHYRIN O.S.F.

Cüm Permissu Superiorum.

ST. LOUIS, MO.

B. $\mathbf{E} \mathbf{E} \mathbf{D} \mathbf{R}$,

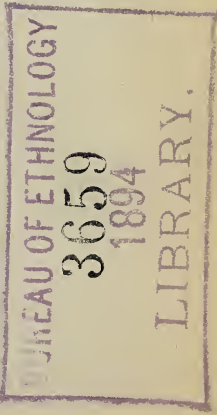


PM1>6:1

$$
\begin{aligned}
& 271 E 6 \\
& 1883 \\
& \text { copyr }
\end{aligned}
$$




\section{NINITCHIANÄ.}

Mäse atawak waiapiskiwätoa anamihäu masenachekanon, mäse miniu kakichkotakan masenachekanon. Wäwepoz miniu nämuk anino masenachekanon, ene tä ene wä mächno kächkenachkoa Anamihan, Jesus ot Äsechzekon. Mamazetawak, mämik tä Omänominewak, kon mäse ot achtananowawon masenachekanon.

Kätin iachpez sanakat ene! Enoch wäwepoz naiämik anamihäu masenachekanon, kakichkotakan masenachekanon miniu, opäsik au kächkenom Jesus ot Äsechzekan, ene kä Katolik Anamihan. Opäsik miniu au kächkenom au äsechzeket, wäwänin asau anochkitawazin Mäz Hawätokon ios achkihe, ene tä nekotäs kesekoch asau äshiat. Ene kaies io osechtawon iom nekot masenachekon, kaies nätom osechtok enoch Mäz Mächkotächkoniäu Fr. Baraga Otchipiwine. Mänawaz neu nesik nenach nikes asachzekem. Nikes tä aton Mäz Anamihan Latinomowine as anamihat Mächkotächkoniäu Mäz Hawätok ot Atuchpone, mawau ncu inäni- 
wak apächnisok miniu asau wichkichtokoa asau änochkitawatoa Mächkotächkoniäwon. Omos masenachekone kinau io kächkenan, au io papamächtamon, au esechzekäon miniu kesekoch asau ishion. Ene masenachekon: "Kächkenohamatwon Kesekoch" äs wechtek, kaies osechtawon omanochneu, mäz aiawik io osechtawon, aiom kakichkotakan masenachekon "Kateshim" äs wechtek, nitchionok io osechtawon. Keketotamawena!

"Wämänominewenesit"

Mächkotächkoniäu.

\section{KA'LESHIM NEKAMON.}

Waieskeseon Hawätok!

Nas tä kat ki sawänemim,

Kwaiachk os pos kächkenamach

Kwaiachkichne Äsechzekon.

Sawänemena iachpez neu,

Kwaiachle asau esetaion,

Mawau eneko kaies äz

Jesus ot Asechzekone. 


\section{KATESHIM.}

Kozemonitwon. - Kit anamihamit?

Nachkomitwon.--Net anamiham kä, Mäz

Hawätok ni kes sawänemik.

K.-Wäki tä wä ean : Mäz Hawätok ni kes sawänemik?

N.-Wenäch ka Mäz Hawätok ni kes menik Anamihan, ene tä ene opäsik käz minitwon kaiesis mesit.

K.-Manätonit tä anamihànon?

N.-Manäton kä, nekoneneu tä nesik aweu ene kwaiachkichne Anamihan.

K.-Ta äs wechtek ene kwaiachkichne Anamihan?

N.-Katolik Anamihan äs wechzekatäu.

K.-Hawäne tä kaies osechtok ene Anamihan, Katolik äs wechtek?

N.-Wenäch Jesus, Mäz Hawätok Okison, kaies osechtok ene Anamihan, Katolik äs wechtek, wenäch miniu nätom näniu pepon kaies kächkenohamowazin mamazetawon ene Anamihan; kachneu tä anäch kes osechtawak kaiäniton anamihanon; kon tä kwaiachkichnenon; ene nesik 
Katolik Anamihan kwaiachk Jesus ot Äsechzekon.

K.-Hawäne tä kätin änamihat?

N.-Eno kä wänamichtach änekochkitähät Jesus ot Äsechzekon, sikahapuasit miniu, wäwänin miniu äsetot, Jesus kaiesis akoamenesit.

K.-Ta äsis kächkiwächzikasitoa änamihatoa kwaiachkichne Anamihan äsichzikätoa?

N.-Anamihäwachtikonikäwak tä.

K.-Ta tä kä as anamihäwachtikonikä?

N.-Jo kä hä: O Wichswone Wäwochneme, misik Wäkiseme, misik Waieskesit Hawätok. Amen.

K.-Wäki wä anamihäwachtikonikä?

N.-Ene kä asau mächkawänemake Mäz Hawätok näniu nekoneneu aiawit, Wäwochneme misik Wäkiseme, misik Waieskesit Hawätok; enechpe tä miniu asau mächkawänemake Jesus kaies tachpänät tchepaiatiko, as kes sikihazin ki tätchiakonawon.

K.-Anamihäwachtilsonikäwakit tä kaiänit äsichziketua? 
N.-Kon ot anamihäwachtikonikänowawon;- ene nesik kwaiachkichne Anamiban äsichzikätoa änamihäwachtikoniketoa.

K.-Wäki ene wä kächkenamä kwaiachk Jesus ot Äsechzekon?

N.-Mäz Hawätok kä o Masenachekone, Mächkotächkoniäwak miniu as kakichkotakätoa, ene wä kächkenamä kwaiachk Jesus ot Äsechzekon.

K.-Wäki tä änamihat pos kätau kächkenach, pos kätau onamichtach miniu, os pos wichkichtok kesekoch os jos ishiat? N.-Nekotoasita neno kä; ene kä iom: 1. 'Tanäseu Mäz Hawätok nekoneneu.

2. Mäz Hawätok kwaiachk tepachíonikäu; maiä‘hno pernatesinit mächno totawäu; mäze pematesinit 1ä kotakehäu, mämik enis, kesanich pematesinit achkihe.

3. Näniu Nekoneneu Mäz Hawätok, Wäwochneme, misik Wäkiseme, misik Waieskesit Hawätık.

4. Hawätok Okison, eno kä Mäz Hawätok Wäkiscme, (Jesus) kes pis mamazetaweheso, kes kotakechtau, kes nipoa miniu tchepaiatiko, kinach ap io, kakik pematesin kesekoch asau menenach. 
5. Ki tätchiakonawak kakik au pematesewak; kon nekotoch pos o näpinowawon.

6. Kon weiak pos o wichkichtonon käkoch asau mächno esetot, asau mächno esekit miniu, konomächtchiu asau menekot Mäz Hawätokon o sawäncch\%ckon; ene nesik Mäz Hawätok o sawänechzekon wä wichkichtawach asau mächno esekeach, kesckoch miniu asau ishiach kes anich pemateseach achkihe.

Ene kätau kächkenach, kätau onamichtach miniu änamihat, asau wä wichkichtok kesckoch asau ishiat, kespin konau müchno esekit.

K.-Hawäne kächkenohamonak kwaiachk Jesus ot Äsechzekon?

N.-Mächkotächkoniäwak kä Katolik Anamihäwigamiko.

K.- Mächkotächkoniäwiwakit ä akiko kaiänit anamihanon kächkenohamawikitoa?

N.--Kon kätin o Mächkotächkoniäwinowawon; nasop Mächko:ächkoniäwak enawak: kärhkenohamawekowak kä, kakichkotakäwak miniu. 
$+\quad$ I.

\section{ONAMICHTAMOAN.}

\section{MÄZ HAW ÄTOK.}

K.-Ta anakach pos mächkamä äsis takik Jesus ot Ärechzekon?

N.-Ene kä enis os pos mächkamä anamihane: "Ne Papamächtawau Mäz Hawätok."

K.- Iawäne kaies osechtok ene anamihan: "Ne Papamächtrawau Mäz Hawätok?"

N. - Winua kä kes osechtawak Jesus o kächkenohamawekomon, metatach nish ene.

K.-Ta keu etamä ene anamihan?

N.-Ene kä ätamä :

1. Ne papamächtawau Mäz Hawätok Wäwochneme, mesas käkoch nähechtok, kaies kesechtok kesik achkäu miniu.

2. Ne papamächtawau miniu Okison Nekoneneu aiawenit, Jesus Christ Täpänemenach. 
3. Waieskesinit Hawätokon kes mamazetawehek, Marion kaiekachkoenit kes ochtateseu.

4. Kes kotakechtau as mäk okemawenit Ponze Pilatan, kes sachsakachkohau tchepaiatiko, kes nipoa, kes nekuahau miniu.

5. Anamachkiach kes ishiu, as näno konakach kes iach apiskau.

6. Kesekoch kes ishiu, mesächsin ot äninianech Mäz Hawätokon Wäwochneme mesas käkoch nähechtok.

7. Ene tä enis au ioch piat, asau pis tepachkonazin pämatesinit, näpenik miniu.

8. Ne papamächtawau Waieskesit Hawätok.

9. Ne papamächton Käz Katolik Anamihäwikamik, käz achpichtisitoa o wetochkatoanowau.

10. Päzetonon kisehekatäwon.

11. Jach apiskak weau.

12. Kakik pematesin. Amen. 
1. Ne papamächtawau Mäz Hawätok Wäwochneme, mesas käkoch nähechtok, kaies kesechtok kesik achkäu miniu.

K.-Hawäne enoch Mäz Hawätok?

N.-Enoch kä Mäz Hawätok äne, kesik kaies kesechtok achkäu miniu kaies kesechtok, mawau miniu täpänechtach.

K.-Wäki kaies ok Mäz Hawätok, as kes osechtok kesik achkäu miniu, mesas käkoch miniu?

N.-Kon käkoch o kes onon, kon kä käkoch kes atawon äiawis, wenä Mäz Hawätok mesas käkoch kaies osechtok; ot änänichtamoan o kikitoan miniu nesik kes au, cne tä mawau käkoch as kes kesechtok.

K.-Ta ächtachniu peponakach kaies äz kesechtok Mäz Hawätok mesas käkoch?

N.- Nekotoasitoa noachk kä metatach noachk tachnäno peponakat sakána, (6000) kaies äz kesechtok Mäz Hawätok kesik achkäu miniu, mesas käkoch miniu.

K.-Ta tachnokon kaies tasetot Mär Hawätok mesas käkoch as kes kesechtok? 
N.-Nekotoasita tachnokon kä kes tasetau.

K.-Kon ä tä pos o kes wichkichtonon Mäz Hawätok os pos kes kesechtok, nemewach nesik os pos tasetot?

N.-Mawau kä pos kes wichkichtau Mäz Hawätok os pos kes kesechtok, nemewach nesik os pos kes tasetot, nekotono nesik os pos kes kikitit.

K.-Wäki tä nekotoasita tachnokon kaies io tasetot Mäz Hawälok, mesas käkoch as kes kesechtok?

N.-Ene kä asau kächkenohamonach au cnim esetaiach miniu kina nap: Nekotoasita tachnokon asau anochkiach, nohekon as kesekach tä asau apeach, Mäz Hawätok nesik asau anochkitawake.

K.-Kakik ä Mäz Hawätok kes tanäseu?

N.-Kakik Mäz Hawätok kes tanäscu, kakik miniu au tanäseu.

K.-Ta anakach aiı Mäz Hawätok?

N.-Mesas neu tanäseu, kesekoch, achkihe miniu, kon ko1änos kon os pos tanäsit. 
K.-Ta nekoch Mäz Hawätok as kächkenach?

N.-Mawau kä kächkenom; kaies pis esekimakach, iochpe miniu äsikimakach, au enim esikimakach miniu, Mäz Hawätok kächkenam; kit änänıchtamoninau miniu kächkenam.

K.-Mawau miniu nämoat Mäz Hawätok?

N.-Mawau kä nämua, iachpez enis käkoch as kiatawach kitähcno. Kon käkoch kiazekatäwon änanametot Mäz Hawätok.

K.-Ta nekoch waichkichtok Mäz Hawätok os pos osechtok?

N.-Mawau kä wichlichtan Mäz Hawätok os pos osechtok, ot änänichtamoan, o kikitwon miniu nesik au.

K.-Pos ki wichkichtomenau tä Mäz Hawätok os pos näwake?

N.-Kon pos ki wichkichtoninawon Mäz Hawätok os pos näwake, kon kä ot oweawenon.

K.-Ene ätamimakach neanckotochkin Mäz Hawätok o Masenachekon: Mäz Ha- 
wätok oskechseko, onächle miniu. Wäki tä kätau etamimakach ene?

N.-Ene kä kätau etamimakach : Mäz Hawätok mesas käkoch nämua, ene tä ene wä etamä: oskechseko. Mesas käkoch miniu wichkichtau Mäz Hawätok asau osechtok, ene tä ene wä etamä: onächke. Kon tä kätin ot oskichsikinon, kon miniu ot onächkenon, kon kä ot oweawenon.

K. - Wäki wä kächkenawake Mäz Hawätok?

N.-Ene kä ene wä kächkenawake Mäz Hawätok, as nämach mawau ot änälıochkon äsis weskewach; as nochtamach miniu Jesus as kes pis kächkenohamawikit Anamihan; ene kä wä kächkenawake Mäz Hawätok.

K.-Wäki łä Wü̈wochneme wä wichsit Mäz Hawätok?

N.-Jesuson kä okisemä"ı; mawau miniu kinach nap kit ohochnemonau Mäz Hawätok, mesas käkoch wenach ki menekonak; ene kä ene Wäwochneme wä wichsit.

K.-Manäwakit tä Mäz Hawätokok? 
N.-Kon o manänowawon, nekot nesik aweu Mäz Hawätok.

K.-Nekot as awit Mäz Hawätok, ta tä ächtuchsit?

N.-Näniu nekot kä Wäwochneme misik Wäkiseme misik Waieskesit Hawätok.

K. - Mäz Hawätok ä aweu Wäwochneme?

N.-Mäz Hawätok kä aweu Wäwochneme.

K.-Mäz Hawätok ä aweu Wäkiseme?

N.-Mäz Hawätok kä aweu Wäkiseme.

K.-Mäz Hawätok ä aweu Waieskesit Hawätok?

N.-Mäz Hawätok kä aweu Waieskesit Hawätok.

K. -Näniwakit tä Mäz Hawätok !

N.-Kon o näninowawon; nekot nesik Mäz Hawätok, näniu nckoneneu kä: Wäwochneme misik Wäkiseme misik Waieskesit Hawätok.

K.-Opäsik tä nekot käz achpechtänetakoseu as nänitoa?

N.-Kon opäsik nekot ot achpechtäne- 
takosenon, tatepa achpechtäsewak Wäwocheıne misik Wäkiseme misik Waieskesit Hawätok; kon miniu nekot onächsemau ot awenon, kakik kes iwak kakik tä miniu au tanäsewak.

K.-Wäki tä tatepa wä achpechtänetakositoa Wäwochneme misik Wäkiseme misik Waieskesit Hawätok?

N.-Nekoneneu kä nesik aweu ot Hawätokesvin, ene tatepa wä achpechtänetakositoa.

\section{ASÄNIWAK.}

K.-Hawäneno opäsik wänesinit eneko Mäz Hawätok kaies osehazin?

N. -Asäniwon kä, mamazctawon miniu.

K.--Hawäneko asäniwak?

N.-Mächno hawätokewak kä asäniwak, kon o weawinowawon.

K.-Ta anakach kaies ahnazin Mäz Hawätok mawau asäniwon echpe kaies kesehazin?

N.-Kesekoch kä mawau kes anäwak. 
$\mathrm{K}$.-Kinis tä miniu mawau kesukoch kos iwakit?

N.-Kon anä kinis o kes inowawon; anä kä kes päzotawak. Mäz Hawätokon tä anamachkiach kakik iskotia kes achpakenekotoa.

K _-Ta nä kaiesis päzitatoa akiko anä asäniwak?

N.--Kes mamenatesewak kä, Mäz Hawätokon kes täp achpechtänemowak.

K.-Tanä tä äsis wichsitoa akiko asäniwak, Mäz Hawätokon anamachkiach kaies achpakinikotoa?

N.--Maze hawätokok, ene kä äs wichzikasitoa.

\section{MAMAZETAWAK.}

K.--Ta kaies äne nätom inäniu Mäz Hawätokon kaies oschekot?

N.-Adam kä kes enau.

K.--Ta kaies äne nätom metämoch?

N.-Ewa kä kes enau.

K.--Akit tä akiko nish, Adam Ewa mawau wächtateseach? 
$1_{6}$

N.-A kiwak kä nish mawau wächtateseach. Mawau kä pematesitoa änekochkoa achkäu aitoa, mamazetawak, mawau miniu waiapiniskitoa, mawau miniu äpisinitoa, mawau anino nish wächtatesitoa. K.--Ta nä tä kaies esetot Mäz Hawätok, as kes oschazin nätom inäniwon?

N.--Jo kä kaies esetot: Achkäu kes au as kes masenatenazin nätom inäniwon weau; oskechsekoch tä kes nächnenotawäu ene tä as kes pemazehazin.

K.-Wäki tä Mäz Hawätok kaies io nächnenotawazin oskechseko nätom inäniwon?

N.-Ene kä kaies io nächnenotawazin, asau otätchiakinit.

K.--Hawänenoch änawazin ki tätchiakonau?

N.-Mäz Hawätokon kä enawäu.

K.--Ta tä kaies esetot Mäz Hawätok as kes osehazin nätom metämochson?

N.--Adamon kä kes nepähäu, ene tä nekot ochpekäkon as kes otachpenamowazin, ene tä kaies ok as kes osehazin nätom metämochson. 
K.-Wäki tä kaies io paketenazin Mäz Hawätok omos ackihe?

N.-Ene kä kaies io paketenazin, asau kächkenawake Mäz Hawätok, asau tapanake, asau papamächtawake miniu, asau io wichkichtawach kesekoch os pos ishiach kes nepäiach achkihe, kakik Mäz Hawätok asau näwake.

K.-Ta anakach Mäz Hawätok kaies áhnazin nätom inäniwon, nätom metämochson miniu.

N.-Mäz monachikone kä kes áhnäu; kaiäz onä ene monachikon.

K.-Wäki tä ächtakik enis mäz monachikone?

N.-Mäse kä maniwitoa mätikoak zaiepazichkoa enis monachikone.

K.-Wäki tä kaiesis kinuawazin Mäz Hawätok nätom mamazetawon mäz mona. chikone?

N.-Kesis kinuawäu kä kat asau metchenik äkotek nekot eno mätik; náweau mäz monachekone zaipazichk eno mätik.

K.--Kes papamächtawäwakit tä Mäz Hawätokon? 
N.--Kon o kes papamäch tawanowawon; natchiakach kä kes mezok ene maienewik, ano as kinochtoa; ene tä as kes käz päzitatoa.

K.-Hawäneno kaies totakotoa as kes päzitatoa?

N.-Maze hawätokon kä kes echpänanekok kinupik kes pis ishinakiho, enetä as kes päzetahazin nätom mamazetawon.

K.--Ta nä tä kaies esetot maze hawätok kinupik as kes pis ishinakosit?

N.-Metämochson kes pis kehomäu asau mezenik ene äkotek mätiko; kes waiäsemäu tä; ene tä metämoch nätom kaies mezik, kachneu tä miniu inäniwon kes achsamäu, ene tä nais as kes päzitatoa as kes kinochtamatoa Mäz Hawätokon, opäsik tä maze hawätokon kes papamächtawäwak.

K.-Kinis tä kes pemateseu Adam nätom inäniu?

N.-Jachpez kä käz kinis kes pemateseu; sakäu tachnoachk misik tä nänino metatach tachnäno pepon kes pemateseu ios achkihe. 
K.-Ta äs wechzekatäk enc päzeton, kaiesis päzitatoa nätom mamazetawak mäz monachikone?

N.-Päzeton kä pis kikeiochtateseach, ene äs wechzekatäk.

K.-Mawau tä mamazetawak, mawau pematesitoa miniu, kes nikanikokit ene päzeton kaiesis päzitatoa nätom mamazetawak?

N.-Mawau kä neu pämatesitoa achkihe kes nekanekok ene päzeton; mawau kä pitawak, kikäskamok ene päzeton, enechpe pis ochtatesitoa ios achkihe. Mawau kä kikes pis kikäskä ene päzeton. Wenä nesik Käz Maria, Jesus Okian, kon o kes kikäskonon ene päzeton pis kikeiochtateseach mawau. Jachpez wenach kes peneseu echpe pis ochtatesit achkihe, kakik kes peneseu.

K.-Ta tä äsis nekanikoiach ene päzeton pis kikeiochtateseach?

N.-Nianon kä kit äsis nikanikoiach :

1. Kon pos o wichkichtonon kitätchiakonau kesekoch os pos ishiat, as kes iachpez kikäskach ene päzeton pis kikeiochtaseach. 
2. Ene kä misik äsis nikanikoiach : Taskiu (saiä) kit änänichtamoweninau; kon pos ki wichkichtoninawon, Mäz Hawätok asau kächkenawake; ene nesik kaiesis kächkenohamonach Jesus, ene wä kächkenawake.

3. Ene misik äsis nikanikoiach ene päzeton : opäsik äsis tatachkeseach asau maze esetaiach, ene tä os pos mächno esetaiach.

4. Mawau wesakesin, mawau kotakechton, anoz miniu käkoch sänakach omos achkihe, ene ächtotakiach ene päzeton.

5. Ene tä ene nianon äsis nikanikoiach, asau nepäiach. Ene kä ene mawau pämatesitoa wä nepäkoa, as kes päzitatoa nätom mamazetawak mäz monachikone, mawau tä kikes pis kikäskä ene päzcton.

K.-Tapech tä käsehekatäk ene päzeton pis kikeiochtateseach?

N.-Saikahapuaseachkin kä, enechpe käsehekatäk. Konomächtchiu sikahapuasit weiak, achpäniu kikäskam ene päzeton pis kikeiochtateseach; kon tä pos o wichkichtonon kesekoch as pos ishiat, 
kespin nepäk konomächtchiu asau sikahapuasit. Ene tä kaies io as akuamechnesit Jesus, mawau mamazetawon asau sikahapuasitoa.

K.-Ta tä Mäz Hawätok kaies echpänanazin nätom mamazetawon as kes päzetonit mäz monachekone?

N.-Kes saketenäu kä käz monachikone, ene tä anoz käkoch asau kotakihisitoa.

K.-Kes mächno esekewak ä nätom kaies pis pematesitoa omos achkihe?

N.-Kon o kes mächno isikinowawon; kes käz maze esekewak, achläniu Mäz Hawätokon kes nächkehäwak.

K.-Kon ä weiak o kes mächno esckenon enechpe?

N.-Nekototak kä nesik kes mächno esekewak: Noe kaiesis wichsit, wewon miniu, näniu okison miniu, näniu onämion miniu; akiko nesik kaies mächno isikitoa enechpe.

K.-Ta tä Mäz Hawätok kaies echpänanazin, anino kaies pis maze pematesinit? 
N.-Mawau kä nipihe kes tachpänähäu, anino nesik Noeán, misik tä Noe wewon, okison, onämion miniu, eneneko kaies pemazehazin.

K.-Ta tä kaies esetot Mäz Hawätok, Noean as kes pemazehazin?

N.-Kes enäu kä Noeán, mäz napichkoan asau osechtonik, asau positoa tä winua, enoch kä: Noe, wewon, näniu okison, näniu miniu onämion, asau positoa miniu mawau manätowon, ochpetawon miniu tachnäno waichsinit; nanikotiwan nesik asau positoa, mawau miniu asau metchikoa asau posichtokoa.

K.-Ta tä kaies esetot Mäz Hawätok kaies posichtoa akiko shuasik kaies mächno pematesitoa?

N.-Kes kimewanechtok tä änikochkoa achkäu niu eno metatach tachnäno kesekot, niu metatach tachnäno wanitipächkon miniu, ene tä mawau kes moskinä achkäu. Metatach nianon ene tachnäno as kozenächkätach kesis pasitäpiu wazeu mamawau äspikä. 
K.-Mawau tä mamazetawak nipihe kes tachpänäwakıt enechpe?

N.-Mawau kä pämatesitoa, mawau miniu manätowak, ochpetawak miniu änekochkoa achkäu nipihe kes tachpänäwak; aki nesik mäz napichkwone kaies positoa, akiwak kaies pematesitoa.

K.-Ta tachni keso eneko kaies iachpez moskinä achkäu?

N.-Nianon keso kä kes iachpez moskinä mawau achkäu, kon poz kotänos wazea o kes nakwaton. Kachneu tä opäsik kes echkatäu, nanas mawau achkäu misik kes pächkoatä.

K.-T’a kaies äz itoa mäz napichkwone akiko shuasik?

N.-Ächpez kä nekot pepon as awik kes iwak mäz napichkoane, ene tä enechpe kaies sakisitoa.

K.-Ta tä kaies esetot Noe kaies sakesit mäz napichkwone?

N.-Kes paketenamawäu kä Mäz Hawätokon paketenekon; mawau kes mamiawamäwak Mäz Hawätokon as kes pemazihikotoa. 
24

K.-Ta tachni pepon kaies pematesit Noe ios achkihe?

N.-Sakäu tachnoachk kä misik nianon metatach tachnäno pepon kes pemateseu.

K. -Ta pe kaies moskinä achkäu?

N.-Metatach noachk misik tä nekotoasita noachk kaies tachni peponakach, kaies äz kesechtok Mäz Hawätok achkäu, mesas käkoch miniu, enechpe kaies moskinä achkäu.

K.-Opäsik kes mächno isikiwakit mamazetawak kaies äz moskinä achkäu?

N.-Opäsik kä kes mächno esekewak, kes kohnäwak Mäz Hawätokon. Achkosik tä äni manätoa, misik kes käz maze esekewak.

K.-Wäki tä kaies isichzilketoa enechpe akiko pematesitoa?

N.-Mawau kä mamawau kes anochkiwak as katäu osichtokoa käz asin kaskachkozekon kaiäz espèke.

K.-Wäki kätau io osichtokoa ene asin kaskachkozekon?

N.-Ene kä kätau io osichtokoa as katäu ispänichsitoa, ächpez mamenatesitoa. 
K.-Kes mininichtamot tä Mäz Hawätok as kes osichtokoa ene asin kaskachkozekon?

N.-Kon o kes mininechtonon Mäz Hawätok ; ene tä mawau kaies io kakaiänit isinisitoa akiko mamazetawon.

K.-Kes kesichtawakit tä ene asin kaskachkozekori?

N.-Kon o kes kesichtonawawon, kon kä o kes nänochtatinowawon, ene tä kaies io ponichtokoa.

K.-Ta tä kaies isikitoa kaies ponichtokoa?

N.-Akiko kaiesis nenochtatitoa kes mamawazehetowak, ene tä kaiesis mamawau minikanichtokoa.

K.-Kes mächno isikiwakit tä kaies äz maiakinisitoa?

N.-Kon o kes mächno isikinowawon; näskänekon kä mawau kes wanänemäwak Mäz Hawätokon, anoz tä. käkoch kes hawätokewak.

K.-Mawau tä pämatesitoa änekochkoa achkäu kes wanänimäwakit Mäz Hawätokon enechpe? 
N.-Kon iachpez mawau o kes wanänemanowawon. Kes onapomäu kä wenach Mäz Hawätok nekotwaiak äs wichsitoa; (Abraham kä, mawau miniu onitcbionächson, ochsechsächson miniu) akiwak Mäz Hawätokon nesik kaies menazihatoa.

K.-Ta äs wichzikasitoa ahiko Mäz Hawätokon kaies onapamokotoa?

N.-Sutau inäniwak ene äs wichsitoa. K.-Hawäneno Mäz Hiıätok kaies allonazin asau kakichkimikatoa Sutau inäniwak?

N.-Moseson kä kaies anon:ızin, liäz mäse miniu nätom iuäniwon Mäz Hawätok kes anonäu, asau kakichkimikotoa Sutau inäniwak, au enim isitatoa, kwaiach k asau isis anochkitawatoa Mäz Hawätokon.

K.-Wäki tä kaies io onapomazin Mäz Hawätok Sutau inäniwon?

N.-Ene kä kaies io onapomazin, Okison Jesuson asau pis ochtatesinit naweau Sutau inäniwon. 
11. Ne papamächtawau miniu Okison Nekoneu aiawenit, Jesus Christ, Täpänemenach.

K.-Wäki tä kaicsis wichkoazichtoasitoa mawau pämatesitoa, päzetone as pis io ochtatesit?

N.-Ene kä k̇uiesis wichkoazichtoasitoa, anamachkiach kakik iskotia asau tanäch. nasitoa.

K.-Kes osimihckokit tä pämatesitoa Mäz Hawätokon kakik iskotia?

N.-Kes osimihekok tä, Okison Säsuson kes pis anonäu; ene tä akiko wänamichtachkoa Jesus ot äsechzekon, saikahapuasitoa miniu, wäwänin miniu äsitatoa eneko Jesus kaiesis akuamechnesit, akiwak kä asau sawänechtakositoa; kakik au onanekosewak kesekoch kes ani pämatesitoa omos achkihe.

K.-Hawäne tä enoch Jesus?

N.-Eno kä Jesus, Mäz Hawätok Wäkiseme, Mäz Hawätok miniu Okison; Mäz Hawätokeu Jesus, mamazetaweu miniu konaı. Kakik Mäz Hawätokeu, kes pis mamazetaweheso tä, as kes pis sikihinach, as kes pemazehenach. 
III. Waieskesinit Hawätokon kes mamazetawehek, Marian kaiekachkoenit kes ochtateseu.

K.-Ta äsikit Wäkiseme äsis Mäz Hawätokit?

N.-Mäz Hawätokon kä okisemik, kon tä ot okiachsenon Wäkiseme äsis Mäz Hawätokit, konomächtchiu as mamazetawihesit.

K.-Ta tä äsikit Wäkiseme äsis mamazetawit?

N.-Käz Marian kä okisemik; kon tä ot owochnenon Jesus äsis mamazetawit. Käz Joseph kes pemehäu nesik, kes mazikihäu miniu Jesuson, kon tä ot okisenon.

K.-Hawäne tä enoch käz Joseph?

N.-Käz Maria kä waiekemazin. Asau pemehazin tä Jesuson, miniu käz Marian, ene nesik kaies io wekemazin.

K.-Hawäne tä kaies ochtatesehazin Jesuson?

N.-Käz Maria kä kes ochtatesehäu, as kakik kaiekachkoit.

K.-Onitchionechseu käz Maria, kekachkoweu tä miniu konau? 
N. Konau kä onitchionächseu käz Maria, konau miniu kekachkoweu. Waieskesənit Hawätokon kä kes pis otächnik, Mäz Hawätok o tatachkesin kes pis akoanäskak, ene tä kaies io onitchianechsit käz Marie, kon tä nckotoch inäniwon o kes kächkenawanon.

K.-Ta anakach kaies tase ochtatesit Jesus?

N.--Minikane kä Bethleheme pisächkiwikamiko, kes tase ochtatesu.

K.-Wäki tä pisächkiwikamiko kaies pis io ochtatesit Jesus?

N.-Ene kä as kächkenohamonach, asau mininechtamach kespin kitämakeseach, asau tapachnenichsiach miniu; ene kä kaies pis io ochtatesit kitämakesine.

K.-Ta pe kaies pis ochtatesit Jesus ios achkihe?

N.-Niueno metatach noachk kaies tachni peponakach kaies äz kesechtok Mäz Hawätok mesas käkoch, enechpe kaies pis ochtatesit Jesus.

K.-Wäki tä kaies pis io ochtatesit Jesus ios achkihe? 
30

N.-Ene kä as kächkenohamonach au enim esetaiach kwaiachk asau isis pematcseach omos achkihe; asau inänibazin miniu kitätchiakonawawon, kakik pematesin kesekoch os pos menenach, ene kaies pis io ishiat Jesus omos achkihe.

K.-Ta äs wechzekatäk ene war.itipächkon echpe wächtatesit Jesus?

N.-Nipatepä Anamihäkesekot.

K.-Ta kaies esekemakach echpech wächtatesit Jesus?

N.-Asäniwak kä kes wechtamowäwak manistanis inäniwon as kes pis ochtatesinit Jesuson. Papik tä manıstanis inäniwak Bethleheme kes ishiwak as awe minazihatoa Jesuson.

K.-Ta misik kaies esekemakach kaies ochtatesit Jesus?

N.-Kaiäz onäsit anách kes pis nakiseu ispämiach; näniu tä käz Okemawak, wanau kaies tanäsitoa, keso wä mochkaha, kes näwäwak anachkon; ene tä as kę wichtamawäwisitoa, Mäz Hawätok Okison as kes pis ochtatesit achkihe. 
K.-Ta kaies äsikitoa akiko näniu käz Okemawak kaies näwatoa anachkon?

N.-Minikane kä Jerusaleme kes ishi= wak, as kes pis natawapamatoa Jesuson, kon tä enis o kes mächkawanowawon; ene tä Beth!eheme as kes ishiatoa, ene tä enis as mächkawatoa.

K.-Ta tä kaies ichpänanatoa Jesucon as kes mächkawatoa?

N.-Kes otchichtchikoanekopawetawäwak kä Jesuson, ene tä as kes paketenamowatoa osawa sonion, käz wichkimiakoa miniu.

K.-Ta tä kaies isikitoa akiko näniu käz Okemawak, kaies ani minazihatoa Jesuson?

N.-Kes kewäwak kä, kes awe azemowak tä as tanachkito, Mäz Hawätok Okison as kes pis ochtatesinit ios achkıhe, asau sawänemenach, asau pemazchenach.

K. Ta kaies esekimakach Jerusaleme, echpe akiko käz okemawak as pimi natawapamatoa Jesuson enis?

N.-Käz okemau kä Herodes, kaies okemawit enechpe Jerusaleme, kes säki- 
seu as kes nochtach, saiä as kes pis ochtatesinit kaiänesewon okemawon, Jesus tä isis wechso.

K.-Wäki tä kaies esetot Herodes as kes säkesit?

N.-Kes enänechtom kä papik asau nänazin Jesuson; kes enänemäu kä: Kespin aiom nitchion enim késekit, nenau machkamik net okemawin, wenäcb tä ásit au okemaweu; kes enänemäu J esuson.

K.--Kes kächkenaweu tä Jesuson as init?

N.-Kes kächkenawäu kä, Bethleheme minikane as init, kon tä o kes kächkenawanon ta anakach ene wekewam as init.

K.-Ta tä kaies esctot as katäu nänazin Jesuson?

N.-Kes enäsehäu kä o sämakänechsenon minikane Bethleheme, mawau asau nänatoa apächnichson nish peponakesinit, opäsik miniu nächänesinit. Kes enänechtom kä: Kespin nänatoa mawau "apächnichsok aiäz nish peponakesitoa, ene tä miniu wenach Jesus asau näne. 
K.-Kes nänäwakit tä mawau apächnichson nish peponakesinit, opäsik miniu x.ächänesinit?

N.—Kes nänäwak kä mawau apächnichson; vish peponakesinit, opäsik miniu nächänesinit, Bethleheme, mesewäu miniu kaies init mawau kes nänäwak.

K.-Jesuson tä miniu kes nänäwakit

N.-Kon o kes nänanowawon; Mäz Hawätok tä asäniwon kes enäsehäu, asau pis wechtamakot käz Joseph, asau osimihazin Jesuson, okian miniu, asau ishiatoa kaiänit achkihe, ene kä Egipte.

K.-Kinis tä kes tanäsewakit Egipte?

N.-Kinis tä kes tanäsewak, kaies iachpez anich pematesit käz okemau Herodes. Kaies nepäk tä, ene as kes pis kewätoa.

K.-Ta kaies esekit Jesus echpe metatach nish ene peponakesit?

N.-Onekehekon kä kes enim witchiwäu Jerusalemo anamihä wikamiko as ishianit, ene tä enis achpäniu anamihäwikamiko as kes tanäsit náweau kächkenohamawikitoa; ene tä winua kächkenohamawikitoa kes käz mamachkatänechtamok kaiesis nipoachkot Jesus. 
34

$\mathrm{K}$ - Ta tachni pepon kaies wekemazin Jesus onekehekon?

N.-Nänino metatach kä tachni pepon kes wekemäu.

K.-Ta anakach kaies tanäsit Jesus as mäk wekemazin onekehekon?

N.-Minikane kä Nazaret kes tanäscu.

K. - Ta tä kaies esekit Jesus echpe nänino metatach peponakesit?

N.-Enechpe kä waiäpetot as kakichkotakät.

K.-Ta anakach kaies ishiat Jesus nawaz, konomächtchiu as kakichkotakä?

N.-Pakoatachkamik kä kes ishiu, ene tä enis niu eno metatach nokon as kes mesachkatawät, as kes anamihat miniu.

K.-Hawäneno kaies nachkiskawazin Jesuson, pikoatachkamik as kes ishiat?

N.-Käz Joan Baptistan kä kes nachkiskawäu as mäk sikahapuasewänit; wenach ap tä Jesus kos sikahapuanik.

K.-L'la kaies esekimakach ächpez sikahapuane Jesus?

N.-Kes nochtawäwak kä Mäz Hawätokon Wäwochneme as kikitinit: "En- 
orsh Ni Kis täpanak; ne käz mininimau." Ene tä, Waieskesit Hawätok wapominiu as kes pis isinakosit, ene tä Jesuson as kes pis onapit.

K.-Ta tachni pepon Jesus kaies papam kächkenohamawekit ot äsechzekon?

N.-Näniu pepon kä kes papam kächkenohamaweko.

K.-Hawäneno kaies onapomazin Jesus, asau witchiakot as mäk papam kakichkotakät?

N.-Metatach nish ene inäniwon kes onapomäu, aniwon tä kaies papam witchiwazin achpäniu, as mäk papam kakichkotakät.

K.- Ta tä äs wichsitoa akiko metatach nish ene inäniwak?

N._Jesus o kächkenohamawekomon, konopoz miniu Jesus o Mächkotächkoniämon, ene kä äs wichsitoa.

K.-Wäki tä kaies pipim esetot Jesus konau as kes kächkenohamawikit?

N.-Mamachkatachkamik kä kaies pimiu esetot: kes inänihäu kä käkipichkinit oskechseko, kes inänihäu miniu käkipäch- 
36

tänit ochtawake, anä miniu näpinik kes pemazehäu; käz mäse ıniniu kaiänit kes pimiu mamatau esetau.

K. -Wäki tä kaics io mamatau esetot Jesus?

N.-Ene kä kaies io mamatau esetot Jesuฯ, asau wapachtähewät o Mäz Hawätokewin. Ano wenach kätin mamazetau kesis pemateseu ios achkihe; konau tä miniu Mäz Hawätok aweu.

IV. Kes kotakechtau as mäk okemawenit Ponze Pilatan, kes sachsakichkohau tchepaiatiko, kes nipoa, kes nekuahau miniu.

K.-Mawau tä eneko kaies nochtawatoa Jesuson, kes otachpenamokit ene kakichkotakan?

N.-Kon o kes otachpenanowawon ene kakichkotakan : käz mäse kon o kes onamichtawanowawon Jesuson; kes sechkanäwak, kes patamäwak miniu.

K.-Ta anakach kaies ishianekot Jesus saiechkanikot as katäu patamekot? 
N.-Ponze Pilatan kä as wekit kes ishianäwak Jesus saiechkanikot; ene tä Ponze Pilatan as kes tepachkonikot.

K.-Ta tä kaies echpänane Jesus kaies anich tepachkonikonit?

N. - Kes säsewahau kä Jesus, kes pasächkipenau miniu minichsakächsion, ene tä as kes sachsakachkoho tchepaiatiko, eno tä as kes tachpänät.

K.-Wäki tä kaies io neläk Jesus tchepaiatiko?

N.-Ene kä kaies io nepäk, kenachap io as katäu sikihenach, as katäu akuachsemenach kakik ikkotia, kaies wichkoazechtoaseach as kes päzetaiach.

K.-Mawau tä pämatesinit ios achkihe kes osimihä kakik iskotia, enechpe kaies tachpänät Jesus anamihäwachtiko?

N.-Ano kä mawau asau sikibazin, kes io nipoa anamihäwachtiko. Kespin tä weiak iachpez kinochtach Jesus ot Äsächzekon, kon wenach onau osimihanon kakik iskotia, kespin kat aninichsit. Eno nesik wä au papamächtawazin Jesuson, akiwak as katäu sawänechtawazin Jesu- 
38

son, akiwak as katäu sawänec tik osito:l, kesekoch asan ishiatıa.

K.-Ta anakach kaies tase sachsakachkoho Jesus tchepraiatiko?

N.-Wazewe kä, Kalvaria äs wechzekatäk, zek minikane Jerusaleme.

K.-Ta pe tä Jesus kaies nepäk?

N.-Sikwone kä, nänokon konomächtchiu as otächzechne Pachk.

K.-Ta äs wechzekatäk ene kesekot, echpe Jesus kaies nepäk?

N.-Käz Anamihäwachtik kesekot kä äsis wechzekatäu.

K.-Ta tachıni pepon kaies pematesit Jesus ios achkihe?

N. - Nänino metatach näniu ene pepon kes pemateseu.

K.-Ta anakach kaies átoch Jesus Wean echpe kaies neräk?

N.-Asepächko kä kes atäu Jesus Weau, k nomächtchiu weiak as paketäneme cuis asepächko. 
V. Anamachkiach kes ishiu, as näno konakach kes iuch apiskau.

K.-Ta anakach kaies ishianit Jesus o tätchiakón kaies ächpez atäk weau tchepaikamiko.

N.-A namachkiarh kä enechpe kes iskriwon Jesus otätchiakon; kon tä enis kakik iskotia, kon miniu kisichnasoune; kaiänctrch kä kes takoa ene.

K.-H:ıwäneko akiko kaies itoa imis Jesus kaies ishiat?

N.-Akiwak kä kaies mächno isikitoa käios, kaies nepäkoa, Jesus konomätchiu as nepäk tchepaiatiko.

K.-Wäki tä kaies io anawichtokoa kesckoch wä ishiatoa akiko kaies mächno isikitoa?

N.-Ene kä kaies io anawichtokoa: kon o kes wichkichtonon kesekoch os pos inhiat Jesus konomächtchiu as nepäk. Wenach kä kaies pachkenamonach kesik, echpe kaies nepäk tchepaiatiko.

K.-Wäki tả Jesus kaies io ishiat imis anamachkiach?

X.-Eı,e kä kaiıs i.hiat, as katäı wech- 
tamawazin enis ainit, kaiesis sawänemazin as kes pemazehazin.

K.-Ta pech tä kaies iach apiskat Jesus?

N. -As näno konakach kä kaies nepäk kes iach apiskau.

K.-Ta äs wechzekaläk ene kesekot, echpe Jesus kaies apiskat?

N.-Pachk, äs wechzekatäu.

VI. Kesekoch kes ishiu, mesächsin ot äninianech Mäz Hawätokon Wäwochneme mesäs käkoch nähechtok.

K. - Ta tachnokon misik kaies wekemazin Jesus o kächkenohamawekomon kaies apiskat?

N.-Niu eno metatach nokon misik kes wekemäu, ene tä misik as kes kächkenohamawazin ot Äsechzekon.

K.-Ta anakach kaies ishiat Jesus niu metatach kaies tachnokonakach kaies iachapiskat?

N.-Kesekoch kes ishiu ene as mesächsä ot ärinianeh Ochnon Mäz Hawätokon mesats käkoch nähechtonik. 
K.-Onächke tä Mäz Hawätok?

N.-Kon ot onächkenon, kon miniu ot oweawenon.

K.-Wäki tä wä etamémakach ene: Jesus mesächsin ot äniniane Ochnon Mäz Hawätokon?

N.-Ene kä wä etamémakach: wenach ap Jesus eneko neu äsis wichkichtok mesas käkoch asau osechtok, äsis wichkichtonik Ochnon; miniu wenach Jesus isis Mäz Hawätokit, Ochnon äsis Mäz Hawätokenit.

K.-Ta anakach ait Jesus iochpe?

N.—Äsis Mäz Hawätokit kä mesas neu tanäseu; äsis mamazetawit tä kesekoch mesächsin ot äninianech Ochnon Mäz Hawätokon; apéu miniu konau Käz Ostiwine.

K.-Nekatamot tä Jesus kesik as pis apét Käz Ostiwine?

N.-Kon o näkatanon; konau kä apéu kesekoch, konau miniu apéu Käz Ostiwine. 
VII. Ene tä enis au pis ioch piat asau pis terachkonazin pematesinit näpenik miniu.

K.-Ta pech tä misik katäu pis ishiat Jesus ios achkihe?

N.-Anich achkewik kä au pis ishin, mawau pämatesinit asau pis tepachkonazin, penatesinit näpenik miniu.

K.-Hawänoko akiko pämatesitoa, hawäncko tä näpikoa?

N.-Maiächno isikitoa kä pämatesitoa enawak, kakik pematesin au tanamok kesckoch. Mäze isikitoa tä näpikoa enawak, kakik au kotakechtawak anamachkiach.

K.-Ta tachnäno Jesus au tepachkonenach?

N.-Nishino kä Jesus kinau tepachkonikonau. Nätom kä kinau tepachkonikonau kıs nepäiach; nanekot kinau tipachkonikonau mawau. Ani achkewik tä mawau mamawau au tepachkonäu pematesinit.

K.-Wäki 1ä wä etamimakach ene:

Jenus au topachkos:äu mawau pematesinit? 
N.-Ene kä wä etamimakach: Au mächno tepahamawäu kies mächno esekenit; au maze tepahamawäu tä kaies maze esekenit.

VIII. Ne papamächtawau Waieskesit Hawätok.

K.-Hawäne enoch Waieskesit Hawätok?

N.-Mäz Hawätokeu kä Waieskesit Hawätok. Ene neu miniu wenach nap äsis Mäz Hawätokit, Wäwochneme äsis Mäz Hawätokit, Wäkiseme miniu äsis Mäz Hawätokit.

K.-Ta äsis wechzekatäk ene kesekot, cchpe Jesus kaies pis enäschazin Waieskesinit Hawätokon, as katäu pis sochkiıähäskawazin o kächkenohamawekomon?

N.-Pentekost tä äs wechzekatäu.

K.-Ta pech tä paichtikonach Waieskesit Hawätok?

N.-Saikahapuanekäiıchkin kä, wäwänin miniı maicnekä achkin nckot käz Sawäı chtakosin. 
44

K.- II äki tä Waieskosit Hawätok äsis menenach?

N.-Mäz Hawätok kä o sawänechzekkon ki menekonau.

IX. Ne papamächton käz Katolik Anamihäwikamik, kaiäz achpechtänetakositoa

o wetochkatoanowau.

K.-Wäki tä ene käz Katolik Anamihäwikamik?

N.-Ene kä mawau änamihatoa änékochkoa achkäu aitoa, kwaiackkichne Anamihan, ene kä, Katolik Anamihan äsichziketoa. Mawau tepa onamichtamok, mawau miniu tepa esetawak, as papamächtawatoa Käz Mächlkotächkoniäwon, Mächkotächkoniäwon miniu.

$\mathrm{K}$-Hawäneko akiko änamihäu witochkatiloa?

N.-Mawau kä Katolik änamihatoa änikochkoa achkäu aitoa, mawau miniu kaiäz achpechtänctakositoa kesekoch äpitoa, mawau miniu kisichnasoane äpitoa, akiwak änamihäu wetochkatitoa. 
K.-Ta tä äsis anamiläu wetochkawakichtoa kaiäz achpechtänetakositoa kesekoch äpitoa?

N.-Kimänazehonawak kä, ki pakichsänemonawak miniu asau keketotamonachkoa winua tä ki keketotamakonawak. K.-Ta tä äsis anamihäu wetochkawakichtoa kisichnasoane äpitoa?

N.-Ki keketotamonowak kä, anoz käkoch miniu ki mächno esetach, winua as katäu akuachsemakichtoa.

X. Päzetone Kisehekatäwon.

K.-Ta pech tä käsehekatäk ki päzetoninau?

N.-Saikahapuanekäiachkin kä, tachnäno miniu wäwänin päketchekäiachkin.

\section{Jach apiskak weau.}

K.-Ta au isikitoa mawau näpikoa echpe anich achkewik?

N.-Mawau kä näpikoa au apiskawak enechpe; mawau otätchiakowawon au nasächkawak weowawon. 
K.-Ta au isikitoa as kes apiskatoa mawau näpikoa?

N.-Jesus kä nishino mawau au isis tepahamawäu; kaies mächno esekenit ot äninianeau áhnäu; kaies maze pematesinit tä o nämachtchione au áhnäu; ene tä asau tepachkonazin mawau.

\section{Kakik Pematesin.}

K.-Pos nipokit tä ki tätchiakonawane?

N.-Kon nekotoch onau näpinowawon, kakik pos pematesewak ki tätchiakonawane.

K.-Ta au esetot Jesus kes ani tepachkonazin mawau pematesinit?

N.-Jo kä kätau esetot: Kaies maze pematesinit anamachkiach kakik iskotia au enäsehäu; kaies mächno pematesinit tä kesekoch au awanäu.

K.-Mitchiniu tä au takuat kisichnasoane kes anich achkewik?

N.-Kon mitchiniu au takon, ene kä nesik kesik, anamachkiach miniu au takik kes anich achkewik.

K.-Hawäne tä kisichnasoane äshiat näpikin? 
N. -Eno kä kisichnasoane äshiat, päzetonechsä as tachpänät, ano tä as tapanekot Mäz Hawätokon näpikin.

K.-Hawäne tä kesekoch äshiat näpikin?

N.-Enoch kä kesekoch äshiat, wäwänin as wänamichtach Jesus ot Äsechzekon, saikahapuasit, wäwänin miniu aianinichsit konomächtchiu as nepäk, iachpez miniu täpanekot Mäz Hawätokon näpikin.

K.-Hawäne tä anamachkiach äshiat näpikin?

N.-Eno kä anamachkiach äshiat, mäz päzetone as tachpänät, wäwänin kat änamihat, kon täpanekot miniu Mäz Hawätokon.

K.-Eno tä nesik o tätchiakowau au ishiat lesekoch, anamachkiach miniu?

N.-Kon otätchiakon nesik pos ot äshianon, weowawon miniu au ishimakaton, kike otätchiak kike weau miniu kesekoch au ishiwak kaies mächno isikitoa; miniu winua tä kaies mäze äsitatoa, kike otätchiak, kike weau miniu anamachkiach kakik iskotia pos ishiwak. 
K.-Ta äsikimakach kesekoch?

N.-Kakik onanekosin kä takoa kesekoch, kakik Mäz Hawätok asau näwake.

K.-Ta tä äsikimakach anamachkiach?

N.-Kakik kotakechton kä takoa anamackkiach kakik iskotia asau tanächnasau, kakik Mäz Hawätok kon asau näwake miniu.

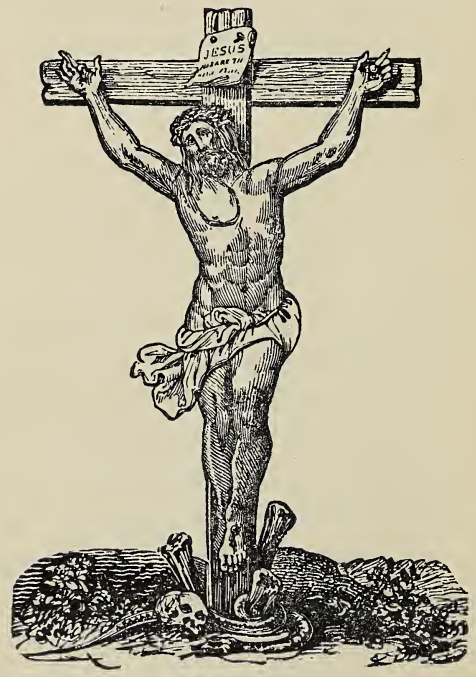




\section{II.}

\section{MÄZ HAW ̈̈TOK OT AIAKO- AMEHNESINON.}

K.-Enit ä neu äsis täpechnä weiak saikahapuasit nesik, enit ä pos äs wichkichtok kesekoch os pos ishiat?

$\mathrm{N}$-Kon isis täpechnenon weiak saikahapuasit nesik, pos onamichtam miniu änekochkitähät Jesus ot Äsechzekon, pos esetam miniu kaiesis akuamehnesit Mäz Hawätok ot aiakoamehnesine.

K.-Ta ächtachnächkin Mäz Hawätok ot aiakoamehnesinon?

N.-Metatach neno kä Mäz Hawätok ot aiakoamehnesinon.

K.-Ta ätamä Mäz Hawätok ot aiakoamehnesinon?

N.-Jo kä ätamä :

1. Nekoneneu Mäz Hawätok mesas käkoch kaies kesechtok; nekoneneu kinau menazehau, änekochkitähäon kinan nekoneneu tapanau. 
50

2. Kon nasop Mäz Hawätok kinau wawechnanon.

3. Anamihäkesekot kinau menazechton. (as apech kesekot.)

4. Kochne kikia miniu kinau menazehawak, kinis asau pemateseon omos achkihe.

25. Pon weiak nähsin.

-.6. Pon päsikoatesenon.

7. Pon kimotenon.

8. Pon kinochkenon asau pahtamat weiak.

9. Pon mohnawenamowin kez pemateseu waiekemazin.

10. Pon mohnawenamowin kez pemateseu käkoch ächtanach.

K.-Ta pe kaies mikit Mäz Hawätok metatach ot aiakoamehnesemon?

N.-Kinis kä Jesus konomächtchiu as . pis ochtatesit achkihe kes meko Mäz Hawätok ot aiakoamehnesinon; Maison (Moses) kes anónäu asáu pis tepatotamenik aiakoamehnesinon Sutau inäniwak. Jesus tä ki kesis akuamemekonau, asau esetaiach miniu kina nap, kaiesis akuamehnesit Mäz Hawätok_ot aiakoamehnesine. 
K.-Ta ätamä naiächtamechne Mäz Hawätok ot aiakoamehnesin?

N.-Jo kä ätamä: Nekoneneu Mäz Hawätok mesas käkoch kaies kesechtok: kinau nekoneneu menazehau, änekochkitähäon kinau nekoneneu tapanau.

K.-Wäki tä äsis akuamemekäiach naiätamechne Mäz Hawätok ot aiakoamehnesin?

N.-Ene kä äsis akuamemekäiach, nekoneneu nesik Mäz Hawätok asau menazehake, iachpez miniu asau tapanake opäsik mawau äsikimakach.

K.-Wäki tä äsis kinuakäiach naiätamechne Mäz Hawtäok ot aiakoamehnesin?

N.-Ene kä äsis kinuakäiach: kat anamihatoa o maze isikiniwau, mawau miniu maze hawätokächkazekon, metäwin, tchisachkiwin, tepapewin miniu.

K.-Kit äsis kinuakemena tä Mäz Hawätok naiätamechne ot aiakoamehnesin, asau menazihakichtoa kaiäz achpechtänetakositoa kesekoch äpitoa?

N.-Kon kit äsis kinuakäninawon asau menazehakichtoa kaiäz achpechtänetako- 
sitoa kesekoch äpitoa; kon kä kit äsis menazehaninawon, äsis menazehake Mäz Hawätok; ki keketotawonawak nesik, asau keketotamonachkoa.

K.-Kit äsis kinuakämena tä, masenechtchekonak asau osihakichtoa, asau kanawehakichtoa?

N.--Kon kit äsis kinuakäninawon masenechtchekonak asau osihakichtoa, asau kanawehakichtoa miniu; kon kä kit äsis hawätokächkazikaninawon mäsenächtchekanat; ene nesik neu asau mächkawänemake Jesus, kaies esekit achkihe as kes pis sawänemenach; kaiäz achpechtänetakositoa miniu kesekoch äpitoa os pos mächkawänemakichtoa, asau kächkenawapamakichtoa miniu, ene wä kanawehakichtoa masenächtchekanak.

K.-Wäki tä wä etamimakach ene, kaies eta Mäz Hawätok: "Pon osichtoa"sinon masininiu; pon asàhsin ispämiach "äpitoa, wachketachkamik miniu äpitoa, "nipihe miniu ächtanäsitoa anamachkiach; "pon otchichtchikoanekapawetawin aki"ko, pon anochkitawin : Nenach kä Täpä- 


\section{3}

nemenon ki Mäz Hawätokim." Wäki wä etamimakach ene?

N.-Ene kä wä etamimakach: Pon osichtoasinon masenäctchekanak as katäu hawätokächkazckäon; iachpez kä käz maze e'setau weiak musenechtchekanon as hawätokächkazekät. Kon tä kit äsis kinuakäninawon, masenächtchekanak asau kanawehakichtoa, asau zenapamakichtoa miniu, Mäz Hawätok asau mächkawäncmake, käiäz achpechtänetakositoa miniu kesekoch äpitoa asau mächlawänenakichtoa; kon tä pachpis kit äsis hawätokächkazekaninawon masenächtchekanak.

K.-Ta älamä äsis nish Mäz Hawätok ot aiakoamehnesin?

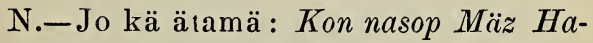
wätok kinau wawechnanon.

K.-Wäki 1ä äsis kinuakäiach äsis nish Mäz Hawätok ot aiakoamehnesin?

E.-Ene kä äsis kinuakäiach, kat asau maze enake Mäz Hawätok, mawau miniu kaiäz achpechtänetakositoa kcsekoch äpitoa kat asau maze enakichtoa. 


\section{4}

K.-Wäki tä äsis akuamemekäiach äsis nish Mäz Hawätok ot aiakomehnesin?

N.-Ene kä äsis akuamemekäiach, Mäz Hawätok achpäniu asau menazehake, eneko kaikitiach, eneko miniu esetaiach.

K.-Ta ätamä äsis näniu Mäz Hawätok ot aiakoamehnesin?

N.-Jo kä ätamä: Anamihäkesekot kinau menazechton.

K.-Wäki tä äsis akuamemekäiach äsis näniu Mäz Hawätok ot aiakoamehnesin?

N.-Ene kä äsis akuamemekäiach, asau menazechtawach (as apech kesekot) Anamihäkesekot, asau anamihaiach, asau mächno esetaiach nesik ene as kesekach.

K.-Wäki tä äsis kinuakäiach äsis näniu Mäz Hawätok ot aiakoamehnesin?

N.-Ene kä äsis kinuakäiach, kat asau anochkiach Änamihäkesekachkin; äsis anochkiach kä tachnänon kesekach, kat asau isis anochkiach Anamihäkesekach.

K.-Ta ätamä äsis niu Mäz Hawätok ot aiakoamehnesin?

N.-Ene kä ätamä : 'Kochne kikia miniu kinau menazehawak, kinis as katäu pemateseon ios achkihe. 
K.-Wäki tä äsis akuamemekäiach äsis nin Mäz Hawätok ot aiakoamehnesin?

N.-Ene kä äsis akuamımichtoa nitchionok asau papamächtawatoa onekehekoawon, asau menazehatoa, asau tapanatoa miniu.

K.-Nitchionok łä nesik akuanemawakit ene?

N.-Kon nitchionok nesik; mawau kä neu änamihatoa naiäwatoa mitchiniu onckehekowawon isis akuamemawak asau menazchatoa, asau tapanatoa, asau mächno totawatoa miniu onekehekowawon au äz pematesinit.

K.-Wäki tä misik äsis akuamemekäiach?

N.-Ene kä misik äsis akuamemekäiach asau papamächtawakichtoa täpänemenachkoa, ki Mächkotächkoniämenawak miniu, mächno nitchionok miniu äsis papamächtawazin onckehekon, asau isis papamärhtawakichtoa täpänemenachkoa. K.-Ta ätamä äsis nianon Mäz Hawätok ot aiakoamehnesin?

N.-Jo kä ätamä: Pon weiak nähsin. 
56

K.-Wäki tä äsis kinuakäiach äsis nianon Mäz Hawätok ot aiakoamehnesin?

N. - Ene kä äsis kinuakäiach, kat asau nätawach keionau, kat miniu asau nänake weiak.

K.-Wäki tä misik äsis kinuakäiach?

N.-Ene kä misik äsis kinuakäiach, kat asau mekànake kez pematesenawak, kat asau nächkihakichtoa, kat asau maze totawakichtoa.

K.-Ta ätamä äsis nekotoasita Mäz Hawätok ot aiakoamehnesin?

N.-Jo kä ätamä: Pon päsikoatesenon. K.-Wäki tä äsis kinuakäiach äsis nekotoasita Mäz Hawätok ot aiakoamehne$\sin$ ?

N.-Ene kä äsis kinuakäiach, mawau maze inänichtamoan, maze kikitwon, mawau päsikoatesin.

K.-Ta ätamä äsis nohekon Mäz Hawätok ot aiakoamehmesin?

N.-Jo kä ätamä: Pon kimotenon.

K.-Wäki tä äsis kinuakäiach äsis nohekon Mäz Hawätok ot aiakoamehnesin?

N.-Line kä äsis kinuakäiach, kat asau 
kimoteach, kat asau waiäsemake miniu kez pematesininau, kat asau kiatawa miniu käkoch mächkàmach.

K.-Ta pos äsetot weiak käkoch mäch$\mathrm{ka}$ ?

N.-Kespin weiak kälsoch mächka, pos kozemosewäu, hawäne ze otinit; au menäu tä anino wätininit.

K.-Ta ätamä äsis shuasik Mäz Hawätok ot aiakoamehnesin?

N.-Jo kä ätamä : Pon kinochkenon asau patamat weiak.

K.-Wäki tä äsis kinuakäiach äsis shuasik Mäz Hawätok ot aiakoamehnesin?

N.-Ene kä äsis kinuakäiach kat asau kinochkeach, kat asau tasemake miniu kez pematesininau, kat asau páhtawake miniu weiak.

K.-Wäki 1ä äsis akuamemekäiach äsis shuasik Mäz Hawätok ot aiakuamehnesin?

N.-Ene kä äsis akuamemekäiach, achpäniu asau onamiach käkoch äiachkin.

K.-Ta ätamä äsis sakäu Mäz Hawätok ot aiakoamehnesin? 
N.-Ene kä ätamä : Pon mohnawenamowin kez pemateseu waiekemazin.

K.-Wäki tä äsis kinuakäiach äsis sakäu Mäz Hawätok ot aiakoamehnesin?

N.-Ene kä äsis kinuakäiach, kat asau päsikoaz enänemake weiak: inäwak isis akuamemäwak kat asau mohnawenamowatoa kaiänesewon metämochson, mämik waiekemewätoa; metämochsok miniu isis akuamemäwak kat asau mohnawenamowatoa kaiänesewon inäniwon, mämik waiekemewätoa.

K.-Ta ätamä äsis metatach Mäz Hawätok ot aiakoamehnesin?

N.-Jo kä ätamä: Pon miniu weiak moknawenamowin käkoch ächtanach.

K.-Wäki tä äsis kinuakäiach äs metatach Hawätok ot aiakoamehnesin?

N.-Ene kä äsis kinuakäiach kat asan mohnawenamowake kez pernatesininau äsis tanachkoa, kat asau kakawäncma. kichtoa miniu kez pematesininawak.

K.-Mitchiniu tä anäch atäwonit aiakoamehnesinon au enim esctaiach? 
N.--Mitchiniu kä nekotoasita aiakoamehnesinon, mawau Käz Mäz Mächkotächkoniäwak kaies osichtokoa.

K.-Ki kesis akuamemekonau kä Mäz Hawätok, asau papamächtawakichtoa Mäz Mächkotächkoniäwak?

N.-Ki kesis akuamemekonau kä, asau papamächtawakichtoa $M a ̈ z$ Mächkotächkoniäwak käkoch äsis akuamenesitoa. Wenach kä Jesus kesis menäu Mäz Mächkotächkoniäwon, Mächkotächkoniäwon miniu, asau wichkichtonik asau kakichkiminachkoa au enim esctaiach.

K.-Wa ätamimakach nekotoasita Mäz Mächkotächkoniäwak ot aiakoamehnesinon, Katolik Anamihäwikamik ot aiakomehnesinon, äsis wechtek?

N.-Jo kä ätamimakach :

1. Kinau menazechton Käz Kesekaton。

2. Kinau anamiham as mäk Mäz Paketenekon, ene kä, as mäk Mäz Anamihan, Änamihäkesekachkin tachnäno miniu Kaiäz Kesekachkin.

3. Kinau wäwänin pakctchekäm tachnäno nckot pel on; kinau wäwänin otach- 
penom Käz Eucharistiwin tachnäno wätächzenächkin Pachk.

4. Kinau mesachkatawäm niu metatach kesekaton konomächtchiu asau otächzechne Pachk. Pon tä miniu metche Anamihäwachtik kesekach metchemechsä.

5. Käkoch kesekechtawon, kinau anamihäu paketenekäm, äsitatoa änamihatoa.

6. Pon wekemin osam kächze änawemat, pon miniu nasewänon, weiak anarnihäu nepawit, echpe wätächzechnächkin as kinuatich.

K.--Ta pos äsis menazechtawach Käz Kesekaton?

N.-Wne kä tepa pos äsis menazechtawach Käz Kesekaton, äsis menazechtawach Anamihäkesekaton.

K.-Wäki tä pos äsetach Änamihäkese. kachkin, Kaiäz Kesekachkin miniu?

N.-Anamihäwikamiko kä pos ishion os pos awe anamiha ächpez Käz Paketenekon, ene kä, Mäz Anamihan, äs wechtek, os pos pächtamä miniu kakichkotakan; kon miniu pos anochkinon ene kesekach, eneko miniu äsis wichkichtok asau mächno esctach pos mächno eseton. 
K.-Enit ä nesik äsis täpechne nekotono nesik os pos paketchekä tachnäno nekot pepon?

N.-Kon isis täpechnenon nekotono nesik os pos paketchekä tachnäno neknt pepon, ene kä äsis weskewach wäwepoz asau paketchekä, konemau nanekot keso; opäsik kä wepoz os pos mächlkawänechtamä mawau päzetonon, kespin wäwepoz as paketchekä.

K.-Enit ä neu äsis täpechne os pos otachpenamä Käz Eucharistiwin tachnäno nesik wätächzechnächkin Pachk?

N.-Kon isis täpechnenon os pos otachpenamä Käz Eucharistiwin tachnäno nesik wätächzechnächkin Pachk; ene kä äsis weskewach wäwepoz asau otachpenamä, konemau nanekot keso, kespin tä wäwänin otachpenamä.

K.-Ta tä pos äsetach ene os pos mesachkatawä niu metatach kesekaton konomächtchiu as otächzechne Pachk, tachnäno miniu äkäiach os pos mäsachkatawäiach ?

N.-Tachnäno kä mesachkatawäu kese- 
kach as nawachkik nesik pos mitchichso, mänawaz tä nächka, kon tä metchemechsä pos metchenon.

K.-Ta pe äsis menekäiach os pos metchach metchemechsä Anamihäwachtik kesekach mesachkatäwä kesekach miniu?

N.-Kaiäz wesakeseach ka, enechpe äsis menekäiach asau metchach metchemechsä Anamihäwachtik kesekach, mesachkatawä kesekach miniu : kespin miniu käkoch kaiänit kat takik; kespin miniu Nipatepä Anamihäkesckot otächzechne nächewä Anamihäwachtik kesekach, metchemechsä pos metchin enechpe.

K.-Wäki tä wä etámä os pos mesachkatawäiach, naianekotochkin miniu kat asau mezach metchemechsä?

N.-Ene kä wä etamä, asau kotakihisiach as päzetaiach. Wenach miniu Jesus kes mesachkatawäu 40 tachnokon; mawau miniu kaiäz achpechtänetakositoa iochpe kesekoch äpitoa wäwepoz kes mesachkatawäwak as mäk pematesitoa achkihe, ene au io mesachkatawäiach kinach ap. 
K.-Mawan tä änamihatoa pos mesachkatawäwakit mesachkatawä kesekach?

N.-Kon mawau änamihatoa o natawänemanowawon asau mesachkatawätoa. Nitchionok, wäskenamitoa miniu, nanas nishino metatach nekot ene (21) as kes peponakesitoa, kon ot inänuwawon asau mesachkatawätoa; ano tä metchemechsä kon onau metchinowawon Anamihäwachtik kesekach mesachkatawä kesekach miniu. Ene tepa miniu waiesakesitoa, kaiäz anochkitoa, kaiäz pemochnetoa miniu, kon poso mäsachkatawänowawon, kespin kat isis wichkichtokoa. Metämochsok miniu naiochnawachsitoa, käkiskawatoa miniu nitchionon, kon pos o mäsachkatawänowawon.

K.-Wäki tä wä etamimakach ene: Kinau anamihäu paketenckäm?

N.-Ene kä wä etamimakach : Änamihatoa Anamihawikamiko aiwatoa, Mächkotächkoniäwon miniu as init, inänechtakosewak asau wetochkawatoa os pos nanahechtakoa anamihäwikamik, asau menatoa miniu Mächkotächkoniäwon au io pematesinit. 
64

K.-Weskewatoat tä, änamihat a $a u$ wekemazin osam käze änawemazin?

N.-Kon weskewaton; kinuawau kä änamihat kat asau wekemazin osam käze änawemazin.

K.-Ta pe tä känuawikimakach kat os pos osechtok wikichtwon nanitwon?

N.-Niu Anamihäkesekat tä konomächtchiu asau otächzechne Nipatepä Anamihäkesekot, nanas tä as Okemau Kesekach; misik tä as mäk käz mesachkatawän 40 kesekaton konomächtchiu asau otächzechne Pachk, rıanas tä as nätom asau Anamihäkesekach kes anich otächzechne Pachk; enechpe känuawekimakach os pos osechtoch wikichtwon nanitwon.

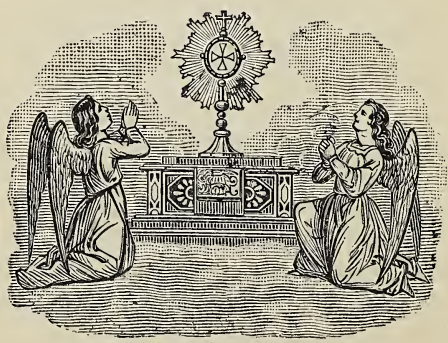


65

\section{III.}

\section{K ̈̈Z SAW ̈̈NECHTAKOSI- NON.}

Kozemonetwon.-Ta ächtachnächkin käz Sawänechtakosinon?

Nachkomitwon.-Nohekon kä:

1) Sihahapuanitwon.

2) Sochkitähäskatwon.

3) Paketchekon.

4) Käz Eucharistiwin.

5) Anamihäu Peme.

6) Mächkotächkoniäwin.

7) Anamihäu Wikichtwon.

K.-Hawäne kaies osechtok anino Sawänechtakosinon?

N.-Jesus kä kes osechtau, ki tätchiakoninau asau inänihazin, kakik onanekosin kesekoch asau menenach. 
66

\section{SIKAHAPUA.VITWON.}

K.-Ta nä ene Sawänechtakosin opäsik mäse kätau enapazechtok?

N.-Sikahapuanitwon kä, ene opäsik kätau käz enapazcchtok. Kon saikahapuasit kon pos o wichkichtonon kesekoch asau ishiat, kes ani pematesit achkihe.

K.-Ta nä äsikimakach Sikahapuanitwon?

N.-Mawau kä päzetonon kesehekatäwon saikahapuanekäiachkin, päzeton pis kikeiochtateseach, mawau miniu eneko kaies pis päzetaiach konomächtchiu as sikahapuanekäiach.

K. - Ta nä misik äsikimakach Sikahapuanitwon?

N.—Ene kä echpe änamibaiach kaies sikahapuanekäiachkin Mäz Hawätok miniu ki pichtikakonau enechpe.

K.-Hawäne tä waichkichtok asau sikahapuasewet?

N.-Mächkotächkoniäwak kä. Weiak tä konomächtchiu saikahapuasit käz wesakesit tä, kon tä käzo as tanäsit Mächko- 
tächkoniäu, mawau pämatesitoa pos wichkichtawak acau sikahapuasewetoa.

K.-Ta nä pos äsetot weiak asau sikabapuasewet kat as Mächkotächkoniäı aiawit?

N.-Ene kä pos äsetot: Nepeu pos sekenamowau wene kätau sikahapuanazin, konau tä pos hewa:

"Ki Sikahapuanin o Wichswone Wä. wochneme misik Wäkiseme, misik Waieskes̄it Hawätok."

K.-Ta tächnäno weiak pos sikahapuanazin?

N.-Nekotono nesik weiak wäwänin pos sikahapuanau: Enoch tä kes sikahapuanekot kat as Mächkotächkoniäwon aiawenit, echpe näwazin Mächkotächkoniäwon, enechpe pos natotamowäu wäwänin asau sıkahapuanekot.

K.-Wäki tä nekotono nesik wä wichkichtawach asau sikahapuanekäiach?

N.-Ene kä nekotono nesik wä wichkichtawach, asau sikahapuanekäiach: ki tätchiakonawak kä kächkewächzikasowak echpe saikahapuanekäiach, kon tä neko- 
68

toch pos kisechkawon ene äsis käthkiwächzikasitoa.

K.-Wäki ene wä esetot Mächkotächkoniäu akuaze iskoachteme as wäpetot as sajkahapuasewezin ?

N.-Ene kä wä esetot: konomächtchiu as sikahapuasit weiak, kon kätin ot anamihanon, kon Mäz Hawätokon wänitchionächsä ot änänemekonon.

K.-Wäki Mächkotächkoniäu mänawaz sewechtakon wä átok otänaniwe saikahapuanazin?

N.-Ene kä wä esetot asau mächkawänochtamach :

$\mathrm{Ki}$ tätchiakonawon asau io inänihazin onamichtamoan, sikahapuanitwon miniu, kon nekotoch asau panatesit, kakik pernatesin asau mene, kespin mächno kanawichtowazin Mäz Hawätokon o sawänechzekon, kaiesis menekot echpe sikahapuane.

K.-Wäki tä Mächkotächkoniäu wä anamihäwachtikonamowazin ochkächne saikahapuanazin.

N-Ene kä wä anamihäwachtikonamowazin asau mächkawänemazin Jesuson, tche- 
paiatiko kaies näpenik; kon nekotoch asau tikisetach miniu Jesus ot Anamihan.

K.-Wäki tä Mächkotächkoniäu wä pichtikanazin saikahapuanazin Anamihäwikamiko?

N.-Ene wä pichtikanazin asau kächkenamä: mawau saikahapuasitoa kesekoch asau pichtiketoa kes anich pematesitoa ios achkihe, äsis pichtiketoa iochpe Anamihäwikamiko, kespin mächno kanawichtokoa Mäz Hawätok o sawänechzekon asıu mächno isikitoa.

K.-Wäki tä Mächkotächkoniäu wä anamihäwachtikonamowazin ochkächne otone miniu?

N.-Ene kä wä esetot asau mächkawänemazin : saikahapuasit käz aiakoamemau kon asau maze kikitit miniu wonach.

K.-Wäki tä Mächkotächkoniäu wä aramihäwachtikonamowazin ochpaniach misik naweau otäne?

N.-Ene kä wä anamihäwachtikonamowazin ochpaniach, tepa otähe, änekochkitähät asau tapanat ot Anamihan; naweau otäne 1ä, sinawaneu asau kotakechtok, 
käkoch äsikitchin, kaiesis kotakänechtach miniu wenach Jesus as kes pemenekonazin ot anamihäwachtikomon.

K.-Wäki tä Mächkotächkoniäu wä átok wapiskikon wene kaies saikahapuanazin?

N.-Ene kä wä esetot, asau isis kächkenamach: iochpe as kes sikahapuasit ot ̈̈tchiakon isis penesewon, wapiskikon äsis penach; kon käkoch päzeton iochpe o käkiskanon mawau päzetonon kisehekatäwon.

K.-Wäki tä Mächkotächkoniäu wä menazin onächke wasachkonenakon kaies sakächnatek?

N.-Ene kä wä menazin wasachkonenakon, asau kächkenamach: mawau kat saikahapuasitoa kiskanitipächkato tase pematesewak; akiko tä saikahapuasitoa, wäwänin miniu kächkinachkoa Anamihan, Jesus ot Äscchzekon, wasinakwatoa tase pematesewak. Ene tepa wasachkonenakon kotänos säkächnatck, mawau wasachkoneu? 
K.-Ta äsikimakach Tächkonatoa?

N.-Ene kä : Tächkoratoa, Wänitchionächsimatoa, äs wechtek, kätau sikahapuaneme, asau kakichkimatoa $o$ nitchionächsowawon asau nipitachnatoa asau kächkenamänik Katolik Anamihan.

\section{SOCHKITÄHÄSKATWON.}

K.-Ta äsikimakach Sochkitähäskatwon?

N.-Sochkitähäskatwon kä cchpe otachpenamach ki pichtikakonau Waicskesit Hawätok, ki menckonau o sawänechzekon; ki moskawänichtamihikonau miniu, wäwänin asau onamichtamach Jesus o kakichkotakan, wäwänin miniu asau esetaiach eneko Jesus kaiesis aiakoamechnesit.

K.-Kon kikes pichtikakoninawon Waieskesit Hawäıok echpe kaies sikahapuanekäiach?

N.--Ano kä kikes pichtikakonau Waieskesit Hawätok echpe kajes sikahapua- 
anckäiach ; Sochkitähäskatwon tä maienekäiach, opäsik ki moskinaniko Waieskesit Hawätok o sawänechzekon.

K.- Ta äsis sawänemenach Waieskesit Hawätok, echpe maienekäiach Sochkitähäskatwon?

N.-Nohekon kä kit äsis sawänemekonau :

1) Waieskesit Hawätok ki kakitawehekonau, ki kächkenohamakonau ächpez waieskesit Mäz Hawäıok Näniu Nekoneneu aweu, ächpez miniu onanekowach kesckoch.

2) Ki menekonau nipoachkon, wäwänin nänochtamach Jesus o kakichkotakan.

3) Ki kächkenohamakonau au esetaiach käkoch sänakach äsikeachkin.

4) Ki sochkitähäskawenemekonan, asau wichkichtawach wäwänin asau esetaiach änenach Mäz Hawätok.

5) Ki moskawänichtamihikonau, kon asau tikisetamach kit Anamihamenau, wäwänin miniu asau kächkenamach atu esetaiach, kwaiachk asau pemateseach. 
6) Ki pechnahamakonau kit änänechtamowenach, asau tapanake Maz Hawätok, wäwänin miniu asau anamihaiach.

7) $\mathrm{Ki}$ maskawänichtamihikonau, kon asau kotamach nepän, kon asau kohtamach miniu asau kotakehekäiach, naskat miniu asau ıähnekäiach, Jesus ot Äsechzekon asau io nähnekäiıch, asau kohtamach tä päzeton.

K-Wäki tä misik ächpenanekäiach Sochkitähäskatwon?

N.-Sochkitähäskatwon kä kit ächpenanekä asau iachpez sochkänechtamach äsis anochkitawake Mäz Hawätok, asau mekatamach miniu asau mekanake maze hawätok, kon asau nochkehenach nanas asau nepäiach.

K.-Hawäne waichkichtok asau mikit Sochkitähäskatwon?

N.-Mäz Mächkotächkoniäu kä nesik.

K.-Ta tachnäno pos waikichtawach asau menekäiach şochkitähäskatwon.

N.-Nekotono kä nesik.

K.-Wäki tä nekotono nesik wä wichkichtawach asau menckäiach Sochkitähäska1won? 
N.-Ene kä nekotono nesik wä wichkichtawach asau menekäiach Sochkitähäskatwon: ki tätchiakonawak kä kächkewächzikasowek, echpe maienekäiach Sochkitätäskatwon, kon tä nekotoch pos kisechkawon ıne äsis kächkiwächzikasiach.

K.-Wäki tä anä kon opäsik wä sochkanamihatoa, kaies minichtoa Sochkitähäskatwon?

N.-Ene kä wä kon o sochlänichtanowawon, kon o papamänechtanowawon Waieskesinit Hawätokon; otähowa aiano kikitotakotoa.

-T'a nä tä au esetot weiak echpe kätau otachpenach Sochkitähäskatwon?

N.-Ene kä au esetot: Wäwänin enechpe pos aninichso, pos paketchekäu; pos penaton äkit; kon miniu anamihäwikamiko mesewäu onau anapenon; wäwänin pos anamihau, pos wechtam miniu ene anamihan waiechtamä, konomächtchiu as miniti Sochkitähäskatwon.

K.-Ta nä ätamä ene anamihan?

N.-Ene kä ätamä: Mäz Hawätok 
Nochne, ki papamächton : net onamichton miniu mawau kaiesis kächkenohamakäion äsis anamihaion.

Kit anomächkon, Waieskeseon Hawätok! Ki pihin asau pichtikäon netähe, asau moskinäskakäian ki sawänechzekon. Ki mamachkatänemin ächpez nähe sawänemeon, ano kes nächkehe. Wächzetau kätin net aninichsim eneko kaiesis päzetaion; wächzetau kätin ki tapanin änekochkitähäion, naszeau kakik kat asau apétaweon netähe; naszeau kat isis sawänechtakosern kaiesis kisechtaseon. Amen.

K.-Ta nä äsetot Mäz Mächkotächkoniäu maikitchiu Sochkitähäskatwon?

N.-Tächninächtchitawäu wene maienazin Sochkitäbäskatwon, keketotamowäu, anamihäu peme menäu, anamihäwachtikonamowäu ochkächne, mänawaz tä miniu pakamawähäu.

K.-Ta äsikimakach ene as keketotamowazin?

N.-Mäz Mächko1ächkoniäu mamiachtamäu enechpe Waieskcsinit Hawäiokon, asau pichtikakot anino maicnazin Sochkitähäskatwon. 
K.-Ta äsikimakach ene, Mäz Mächkotäcbkoniäu as tächninächtchichtawazin niaienazin Sochkitähäskatwon?

N.-Echpe kä Mäz Mächkotächkoniäu taiächninachtchichtawazin, kaickketotamowazin miniu, enechpe paichtikakonit Waieskesinit Hawätok.

K.-Wäki tä Mäz Mächkotächkoniäu wä anamihäwachtikonamowazin ochkächne?

N.-Ene kä wä anamihäwachtikonamowazin ochkächne, kon nekotoch asau tiki. setach Jesus ot Äsechzekon.

K.-Wäki tä Mäz Mächkotächkoniäu wä pakamawähazin mänawaz maienazin Sochkitähäskatwon?

N.-Ene kä wä pakamowähazin mänawaz, asau kächkenohamonach mamawau, kon asau nächkänimakichtoa nächkositonachkoa, nächkäniminachkou, sinawaneu achpäniu asau kotakänechtamach käkoch äsikeachkin, naskat miniu asa'ı nähnckäiach, Mäz IIawätok miniu o kikitwon as:ı io näbnekäiach. 
K.-Ta tä au esetot weiak kes ani mene Sochkitähäskatwon?

N.-Pemäz kä au otchichtchikoanekapaweu, asau mamiawamazin Mäz Hawätokon, au enänechtam tä:

"৯ätin ne sawänochtakosim as kes menekäion Sochkitähäskatwon; kon nekotoch nenau wanänechtanon net Anamihan." Ene tä oti asau wechtach ene anamihan waiechtamä, kaies ani miniti Sochkitäbäskatwon : "Kit anomächkon Waieskeseon Hawätok! Ki mamiawamin kaiesis sawanemeon iochpe, Sochkitähäskatwon as kes menekäion. $\mathrm{Ki}$ mänazehin änekochkitähäion. $\mathrm{Ki}$ mamiachtomin asau sawänemeon, kakik kesekoch asau onanekoseon. Kanawehena kon käkoch asau nochkehekäion net änänechtamoane mäte; sawänemena asau mächno pemateseon, kes nepäion tä, kesekoch kakik asau wez tanachkiamenon." Amen. 


\section{PAKETCHEKON.}

K.-Ta äsikimakach Paketchekon?

N.-Päketchekäiachkin kä ene kässehamakäiach ki päzetoninawon, eneko kaies maze esetaiach kaies äz sikahapuanekäiach.

K.-Tachnäno tä weiak päketcheket kisehekatäwon o päzetonon?

N.-Kon tachnäno weiak päketcheket kisehekatäwonon o päzetonon; ene nesik änekochkitähät aianinichsit, wäwänin miniu päketcheket, eno au käsehekatäk o päzetonon.

K.-Hawäne kaies osechtok ene Paketchekon?

N.-Wenach kä Jesus kes osechton, iom as kes enazin o Mächkotächkoniämon : "Hawänetok au kisehamawäk o päzetonon, enoch au kisehekatäkin; hawänetok tä kat au kisehamawäk o päzetonon, kon au kisehekatäwon."

K.-Ta nä misik kaies enazin Jesus o Machkotächkoniämon?

N.-Ene kä misik kaies enazin: "Ene- 
koch au kächpetawäk ios achkihe, au kächpezekatäu miniu kesekoch; enekoch tä au pächkonamek ios achkihe, au pächkonekatäı miniu kesekoch.”

K.-Wäki tä kaiesis menazin Jesus mawau Mächkotächkoniäwon ene as kes enazin?

N.-Kesis menäu kä mawau Mächkotächkoniäwon tatachkesin, asau wichkichtokoa asau kisehamawatoa wäwänin päketchekänit o päzetonowawon; Jesus o wichswon asau io kischamawatoa.

K. -Wäki tä au esetot weiak wäwänin asau paketcheket, asau kisehamoch o pätonon päketchekäzin?

N.-Nianon kä ene pos äsetot:

1) Pos nanakatawanechso.

2) Pos aninichso.

3) Pos enänechtam : "kon misik nènau päzetonon."

4) Mawau eneko kaies päzetot pos wechtamowäu Mächkotächkoniäwon.

5) Wäwänin miniu kotákehäso as kes päzetot. 
K.-Wäki tä ene nanakatawänichswon?

N._Ene kä asau mächkawänechtach kaiesis päzetot kaies äz paketchet; konopoz miniu kaies äz sikahapuane.

K.-Wäki tä au esetot änamihat kunomächtchiu asau nanakatawänichsit?

N.-Pos anamihau kä, Waieskesinit Hawätokon au mamiachtomäu asau wasinakwot menekot, mawau asau mächkawänechtach eneko kaies päzetot.

K.-Wäki tä au esetot weiak, wäwänin mawau asau mächkawänechtach o päzetonon?

$\mathrm{N} \cdot$-Pos nanakatawänechso kä eneko kaies maze inänechtach eneko miniu kaies maze kikitit, eneko miniu kaies maze esetot, kespin miniu weiak kon as kes esetot käkoch eneko äiakoameme asau esetot.

K.-Jachpez weskewat one, wäwänin asau nanakatawänichsit?

N.-Jachpez kä käz weskewat ene, wäwänin asau nanakatawänichsit konomächtchiu asau paketcheket; kespin kä weiak wäwänin kon nanakatawänichsit, kon miniu wäwänin onau paketchekenon. 
K.-Wäki au esctot weiak kes ani nanakatawänichsit?

N.-Kes ani nanakatıwänichsit kä, änekochkitähät pos aninichso as kes päzetot.

K.-Wäki tä änamihat kätau io aninichsit as'kes päzetot?

N.-Ene kä änamihat kätau io aninichsit; as kes nächkehazin Mäz Hawätokon as kes päzetot. Jachpez Mäz Hawätokon ki tapanik; acbpäniu miniu ki tapanik, wänitchianä kit ächpänonik.

K. - Wäki tä au esetot weiak kes anich aninichsit?

N.-Kes anich aninichsit kä, iom pos inänechtach: "kon misik nenau katäu esekenon. Konau tä miniu Mäz Hawätok pos pakichsänemäu asau moskawänechtamihikot, wäwänin asau sechkatach mawau päzetonon.

K.-Jachpez kä.weskewat ene, weiak asau aninichsit, iom miniu asau inänechtach : "kon misik nenau katäu esekenon?"

N.-Ene kä ene aiachpez weskewach; kespin kä weiak wäwänin kat aninichsit änekochkitäbät, iom miniu kat inänech- 
8\%

tach: "kon misik nenau katäu esekenon; kon Mäz Hawätokon onau ponikitätakonon kaiesis päzetot.

K.-Wäki tä misik pos äsetol weiak, asau ponikitätakot Mäz Hawätokon kaiesis maze esekit?

N.-Mächkotächkoniäwon kä au nasächkawäu, mawau tä au wechtamawäu eneko mächkawänechtach kaies maze esekit kaies äz paketcheket oti.

K.-Ta nä pos äsetot änamihat naiasächkawazin Mächkotächkoniäwon?

N.-Pos otchichtchikoanetäu kä, iom tä au pakichsänemäu Mächkotächkoniäwon: "Keketotamowena, nochne, ne kes käz päzetom."

K.-Ta tä misik pos äsetot?

N.-Pos anamihäwachtikonikäu kä,ene tä asau wechtach ene anamihan: "Newechtamowau Mäz Hawätok."

K.-Mawau tä pos wechtam o päzctonon weiak as paketcheket?

N.-Mawau kä pos wechtam o päzetonon enechpe as paketcheket, eneko as mächkawänechtach kaies äz paketcheket. 
aiatchkwot. Kespin tä weiak kon nekotoch paketcheket, aiäz pematesit eneko kaies maze esetot pos wechtam; konopoz miniu eneko kaies maze esetot kaies äz sikahapuasit.

K.-Jachpez tä käz maze esetau weiak kaiatok anä o päzetonon pakctchekäzin?

N.-Jachpez kä käz maze esetau; kon miniu pachpis onau kisehanowawon weiak encko kaies mazo esetot, kespin kiatok anä o päzctonon.

K. - Ta nä tä pos wechtach weiak o päzctonon?

N.-Kaiesis nänochtoch kä au isis keketo; tachnäno miniu kaies maze esctot käkoch, pos wechtam.

K.-Ta nä tä au esetot woiak kat anamihätawakät Mächliotächkoniäwon, asau kisehekatäk o päzetonon?

N.-Misik kä pis paketcheket, tepa au isis wechtam eneko kaies wechtach as kes paketcheket iskoaz.

K.-Wäki tä au esetot weiak kes ani paketcheket? 
84

N.-Pus wechtam enc anamihan: "Mäz Hawätok Nochne, wächzetau net aninichsim." Wäwänin tä miniu pos esechzekäu kotakiheswon, eneko kaiesis menekot Mächkotächkoniäwon ; käz weskewat tä miniu, opäsik eneko kaiesis menekot Mächkotächkoniäwon, asau isis minisit kotakiheswon.

K.-Wäki tä pos äsetot weiak asau kotakihesit?

N.-Pos anamihau kä weiak asau kotakihosit, konopoz miniu pos mesachkatawäu, konopoz miniu poz sawänemäu kätemakesinit.

Kisehamatwon Sawänechzekan.

K. - Ta nokoch kaies menenach Jesus käz Sawänechtakosinon kätau io kisehamakäiach ki päzetoninawon?

N.-Nish kikes menekonau, ene kä, Sikahapuanitwon, Paketchekon miniu; ene wä kisehamakäiach ki päzetoninawon.

K.-Wäki waichkoazichtoasit as päzetot? 
N.-Kotakechton kä wichkoazichtoaso. Kespin käz maze esetot weiak, kakik kotakechton anamachkiach wichkoazichtoaso; kespin tä mänawaz nesik maze esetot, kon kakik kotakechton o wichkoazichtoasinon, ano tä wichkoazichtoaso miniu wenach asau kotakechtok, konopoz omos achkihe, konopoz enis kishichnasoane.

K.-Ta pe weiak maiakonamo kakik kotakechton?

N.-Weiak kä wäwänin aianinichsit, päketcheket miniu, enechpech tä maiakonamo ene kakik kotakechton, kaiesis wichkoazichtoasit, as kes käz maze esetot.

K.-Mawau tä miniu kaiänit kotakechton enechpe miakonamawau?

N.-Kon, ene nesik kakik kotakechton anamachkiach ächtakik miakonamo; mitchiniu tä änänechtakoseu asau kotakihesit ios achkihe; kespin tä achkihe wäwänin kat kotakihesit, pos kotakechtau kishichnasoane.

K.-Kon ä weiak pos o wichkichtonon asau miakonamowazin ene kotakechton kishichnasoane ächtakik? 
86

N.-Au miakonamowan kä ene kotakechton, kespin iachpez wäwänin kotakihisit omos achkihe, konopoz miniu wichkichtoasit ene Miakonamatwon Sawänech. zekan.

K.-Ta äsikimakach Miakonamatwon Sawänechzekan?

N.-Kespin kä weiak wichkichtoasit Kesehamatwon Sawänechzekan, miakonamawau kotakechton kaiesis wichkoazichtoasit ios achkihe, konopoz miniu kishichnasoane, as kes päzetot.

K.-Päzetonon tä wciak miakonama. wau kespin wichkichtoasit Kisehamatwon Sawänechzekan?

N.-Kon päzetonon miakonamowanon, kotakechton nesik miakoamowau. Asar miakonamakäach ki päzetaninawon, Jesus kikes menekonau Sikahapuanitwon, $\mathrm{Pa}$ ketchekon miniu.

K.-Hawäne tä waichkichtok asau mikit Miakonamatwon Sawänechzekon?

N.-Käz Mächkotächkoniäu mamawau naikanisitoa, miniu tä mawau Mäz Mächkotächkoniäwak. Käz Mäz Mächkotäch- 
koniäu menäu Miakonamatwon Sawänechzekan mawau änamihanit änckochkoa achkäu ainit; Mäz Mächkotächkoniäwak tä menä wak änamihanit, eneko miniu winua künawchatoa.

K.-Ta nekoch Miakonamatwon Sawänechzekan?

N.-Nish kä, ene Käz Kisehamatwon Sawänechzekon, miniu tä Miakonawatwon Sawänechzekonechson.

K.-Ta äsikimakach Käz Kisehamatwo॥ Sawänechzckon?

N.-Kespin weiak wichkichtoasit Käz Kischamatwon Sawänechzckon, mawau neu kotakechton miakonamowau, eneko kaicsis wichkoazichtoasit ios achkihe, mi. sik tä kishichnasoane, as kes päzetot.

K.-Ta tä äsikimakach Miakonawatwon Sawänechzekonechson?

N.-Kespin tä weiak wichkichtoasit Miakonawatwon Sawänechzekonechson, anä tä kotakechton miakonamowau, eneko kaies wichkoazichtoasit ios achkihe, niniu tä kishichnasoane, as kes päzetot. 
88

K.-Wäki tä au esetot änamihat asau wichkichtoasit Kisehamatwon Sawänechzekon?

N.-Näniu kä ene pos äsetot :

1) Wäwänin pos aninichso änekochkitähät, pos paketchekeu miniu.

2) Pos otachpenäu miniu wäwänin Käz Eucharistiwin.

3) Kwaiachk tä miniu pos esetau mawau eneko as enazin Käz Mäz Mächkotächkoniäu, echpe as mesit Kisehamatwon Sawänechzekan.

K.-Winua nesik änamihatoa ios achkihe as pematesitoa enapazechtawau Kisehamatwon Sawänechzekan?

N.-Kon winua nesik as pematesitoa achkihe ot enapazechtonowawon; wichkichtau neanekotochkin änamihat asau menazin ene Sawanechzekan kishichnasoane äperit, winua asau enapazechtokoa, wepoz tä kesckoch asau ishiatoa. 


\section{KÄZ EUCHARIS'TIWIN.}

\section{K.-Wäki tä Käz Eucharistiwin?}

N._Ene kä Jesus Weau O Mächkom minill, pachkishikon somenapo miniu ot äsinakosine, ene as kiasit Jesus äsis Mäz Hawätok äsis mamazetawit miniu.

K.-Hawäne tä kaies osechtok Käz Eucharistiwin?

N.-Jesus kä kes osechtau Käz Eucharistiwin.

K.-Tape kaies osechtok?

N.-Nekot kesekot kä konomächtchiu as nepäk enechpe kaies oseclitok.

K.-Ta tä kaies esetot Jesus as kes osechtok Käz Eucharistiwin?

N.-Ene kä kaies esetot: "Oti as kes wechpomazin o kächkenohamawekomon, pachkishikon kes otachpenäu, kes anamihätawäu, kes pochkonäu, kes nänichtowäu tä miniu anino o kächkenohamawekomon (o Mächkotächkoniämon), as kes enazin : Otachpenamokon, mezekon miniu mawau: "Jom kä Neau. Ene tepa miniu somenapo kes otachpenam, as átek anamihäu koa- 
90

penakone, kes anamihätam, kes menäu miniu o kächkenohamawekomon, as kes enazin: "Otachpenamokon, menäkon miniu mawau, Jom kä Ne Mächkom, kinua au io sekechnä, mäse miniu mamazetawak, asau ponikitätakotoa Mäz IIawätokon päzitatoawin."

K.-Wäki tä kaies eta Jesus kaies anich osechtok Käz Eucharistiwin?

N.-Ene kä kaies enazin o Mächkotächkoniämon: "Ene iom au enim esetaiek, achpäniu asau mächkawänemeäk. Ene tä enechpe as kesis menazin o Mächkotächkoniämon asau wichkichtonik miniu winua asau osichtokoa Käz Eucharistiwin.

K.-Wäki tä kaies io osechtok Jesus Käz Eucharistiwin?

N.-Ene kä kaies io osechtok, kakik asau wckemena Käz Eucharistiwine; asau mächkawänemake miniu kaies echpänane as kes sikihina; asau sochkänichtamihinazin miniu ki tätchiakonawon tachnäno wätachpenamächkin Käz Eucharistiwin.

K.-Hawäne eno änonazin Jesus, Käz Eucharistiwin asau osechtonik? 
N.-Mawau kä Mächkotächkoniäwon anonäu Jesus asau osechtonik Käz Eucharistiwin konau miniu enänemäu asau wichkichtonik asau osechtonik.

K.-Tape Mächkotächkoniäwakwäsichtokoa Käz Eucharistiwin?

N.-Ächpez kä Mäz Anamihan, eno kä, enechpe as käz paketänamowatoa Anamihäwikamiko mip.

K.-Wäki ene Mäz Anamihan?

N.-Paketenckan kä Mäz Anamihan. Tepa kä kaiesis paketänichsit Jesus tchepaiatiko as kes pemazchazin ki tätchiako. nawon, ene tepa äsis paketänichsit tachnäno as mäk Mäz Anamihan mip; paketcnamowäu kä Weau o Mächkon miniu Ochnon Mäz Hawätokon, Mächkotächkonäwon onächke.

K.-Ta ächtachniu wanäke Mäz Anamihan?

N.-Näniu kä: as paketcnamä, as ispänamä, as otachpenamä miniu Käz Eucharistiwin.

K.-Wäki 1 ä pos äsetot änamihat, echpo Mächkotächkoniäu zenopächtachkin Jesus o Kikitwon? 
N.-Pos nipiton kä, pos anamihäwachtikonikäu miniu, konau miniu pos inänechtam :

Opäsik pos nemäninechton, mesas käkoch asau kotakechtawon, naskat miniu os pos nähnekäion, ene tä os pos paketänechtamon Jesus ot Äsechzekan.

K.-Wäki tä Mächkotächkoniäu nähe paketenamowazin Mäz Hawätokon as mäk Mäz Anamihau?

N.-Pachkishikanon kä somenapo miniu nähe paketenamowäu; mawau tä änamihatoa encko aitoa anamihäwikamiko, enechpe räkitinamawatoa weowawon o tätchiakowawon miniu Hawätokon, wenach nesik asau anochkitawatoa.

K.—W äki tä pos äsetot änamihat echpe äspenamächkin Käz Ostiwin, anamihäu koapenakore miniu Jesus o Mächkom?

N.-Pos menazehäu kä Jesuson as äpenit pachkishikon ot äsinakosine, somenapo miniu ot äsinakosine; wäwänin au onamichtawäu Käz Eucharistiwine, au anamihätawäı miniu. 
K.-Ta tä pos äsotot woiak, echpo Mächkotächkoniän wätachpenachkin Käz Eucharistiwin?

N.-Änekochkitähät kä pos enänechtam: Nastä miniu nenach nap kat otachpenamon Käz Eucharistiwin. Pos anamihau tä, asau kakezemazin Mäz Hawätokon, asau ponikitätakot as kes päzetot; pos inänechtam miniu: kon misik nenau katäu päzetanon.

K.-Hawäneno Mächkotächkoniäu wä Mäz Anamihat?

N.-Mawau kä änamibanit achkibe ainit, mawau miniu kishichnasoane äpenit io Mäz Anamihau Mächkotächkoniäu.

K.-Wäki tä wä menazechtoch Käz Eucharistiwin?

N.-Jesus kä apéu Käz Eucharistiwine, äsis Mäz Hawätokit, äsis mamazetawit miniu; ene imis Jesus Weau, O Mächkom miniu, ene wä menazechtoch.

K.-Jesus Weau tä nesik átäu pachkishikon ot äsinakosine?

N.-Kon Weau nesik atäwon, o Mächkon konau atäu. 


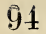

K.-Jesus o Mächkom tä nosik somenapo ot äsinakosine atäu?

N.- Kon o Mächkom nesik atäwon, Weau konau átäı.

K.-Wäki tä wä onamichtamä, as apót Jesus Käz Eucharistiwine?

N.-Wenäch kä Jesus kes heva asau pis apét Käz Eucharistiwine; kon tä nekotoch o känochkenon, kon miniu käkoch ot anawechtonon, ene wä onamichtamä.

K.-Mächkotächkoniäu päzkinachkin Käz Ostiwin, pozkinamoat tä miniu Jesus Weau?

N.-Kon o pozkinanon Jesus Woau, ene nesik pachkishikon ot äsinakosin päzkin. amä. Ano mäse tachnäno päzkinamächkin, ene neu tachnäno apét Jesus äsis Mäz Hawätokit, äsis mamazctawit miniu.

K.-Wäki tä wätachpenamä tachnäno wätachpenamächkin Käz Eucharistiwin?

N.-Jesus kä kit otachpenonau äsis Mäz Hawätokit, äsis mamazetawit miniu Weau o Mächkom miniu. Kätin kä Jesus apéu pachkishikon ot äsinakosine. 
K.-Jachpez tä ki mächno totakonau Jesus paichtikanachkin Käz Eucharistiwino äpit.

N.-Jachpez kä ki mächno totakonau : o sawänechżekan ki menekonau; ki sochkitähäskakonau miniu asau mächno esekeach, asau pakichsänichtamach miniu, kesekoch asau ishiach kes nepäiach.

K. -Ta tä äsis sawänechtakosit maiäch. no otachpenach Käz Eucharistiwin?

N. Niu eno kä isis sawänechtakoseu maiächno otachpenach Käz Eucharistiwin :

1) Jesuson kä enechpe kikäskawäu weo.

2) Käz sawänemik tä enechpe Jesuson。

3) Sochkitähäskak kat asau maze esekit.

4) Isis kächkahamak kesckoch asau ishiat kes ani nepäiach.

K.-Ta tä pos äsetot weiak os pos mächno otachpenach Käz Eucharistiwin?

N.-Wäwänin kä pos nanakatawänech-i so, käkoch mäto kat asau átek otähe, wäwäniu miniu pos aninichso; iachpez wäwänin pos paketchekäu, kon käkoch päzeton pos o kiatonon; kätin pos ona. 
96

michtawäu Jesuson as apénit Käz Eucharistiwine; nekoneneu au is tapanäu, kon miniu weiak pos o sechkananon.

K.-Wäki tä misik pos äsetot weiak os pos mächno otachpenach Käz Eucharistiwin?

N.-Aiäz apächtau tepächka kä kon käkoch pos o metchenon, kon miniu käkoch pos o mänenon; kon miniu kotänos pos ot änapenon ächpez änamihazin. Kon weskewaton, osam weiak kat as weskewach oposächkakanon, kon miniu weskewaton, osam weiak as sasákat kätau otachpenachkin Käz Eucharistiwin.

K. -Ta tä pos änänechtach weiak saiä käze katäu otachpenach Käz Eucharistiwin.

N.-Ene kä pos änänechtach: Kätin apéu Jesus Käz Eucharistiwine. Pos mamachkatänechtam ächpez kishiatesinit, ächpez käz áchpechtänetakosinit; kätin nenau wetapemik mamazetau, as kes inänechtach. Pos aiakoamänechso, pos nanakatawänechtam eneko kaies maze esetot; wäwänin pos aninichso, one tä asit opäsik 
asau sochkänechtach, änekochkitähät asau tapanazin Jesuson, asau kächkenawapamazin. Ene kä pos änänechtach weiak saiä käze katäu otachpenach Käz Eucharistiwin.

K.-Wäki tä misik pos äsetot weiak saiä kes nipitot as awe otachpenach Käz Eucharistiwin?

N.-Kon käkoch pos osenon, ene nesik achpäniu otähe asau mächkawänemazin Jesuson, asau tapanazin miniu. Ene tä kespin saiä katäu otachpenamon Jesus Weau Mäz Hawätok Nekoneneu, sinawaneu pis nasächkach käz atuchpon. Mächkotächkoniäu tä pis kochkehat, tachkonach tä onächke Käz Ostiwin, enechpe nikitchkitach, nänino tä pakachsinon kichpaniach, iom tä eta: "Täpänemeon, kon netäp achpechtänetakosinon, os pos pichtikäon neau, nokot kikitwon tä nesik eta, ene asau inänit ne tätchiak." Wapiskikon asau känonenechpe änamihat; asau motenekot Mächkotächkoniäwon mänawaz pos ispächkitau, sinawaneu pos koch- 
98

tam; ene tä kes nipitatoa mamawau, miniu wenach pos nipitau, asau awe otchichtchikoanekapawit misik, one tä wäwänin asiu mamiawamazin Jesuson kaies pichtikakot otähe; misik tä pos anamihau, kinis miniu kon pos o sakesinon; kinis miniu kon pos o sächkinon. Pochz apächtau tipachekòn, konopoz opäsik kinis, pos mamiawamäu Jesuson, kaiesis sawänemazin.

K.-Iachpez tä mächno esetau änamihat wäwepoz otachpenächkin Käz Eucharistiwin?

N.-Iachpez kä mächno esetau weiak as sawänechtakosit tachnäno keso. Kon weiak pos o wichkichtonon os pos mächno esekit kespin kat wawepoz otachpenach enoch Jesus Mäz Hawätok Käz Eucharistiwine äpit.

K.-Mächno esetawakit tä wäske pemiltesitoa wäwepoz as otachpinachkoa Käz Eucharistiwin.

N.-Iachpez mächno esekewak. Ninitchianä! kespin katäu kanawechtawon pe- 
netähän, wäwepoz paketchekenon, nanekot keso, konopoz opäsik mäse, kespin Mächkotächkoniäu inänechtach ; otachpenach miniu Jesus Weau, Käz Eucharistiwine äpit; kinau maskawänichtamihik 'Täpänechzekät, achpäniu asau peneteseon äsis owcaweon, äsis otätchiakion miniu.

K.-Iachpez maze esetau weiak mäze otachpenächkin Käz Eucharistiwin?

N.-Iachpez kä maze esetau; nanawechtau Jesus Weau, käz nächkehäu Mäz Hawätokon, panazehäu o tätchiakon. Kespin kat wäwänin aianinichsit, au anemeseu kakik iskotia anamachkiach.

K.-Hawäne tä enoch mäze otachpenach Käz Eucharistiwin?

N. Eno kä mäze otachpenach Käz Eucharistiwin, kat mawau aiátotatach o päzetonon päketchekäzin, kat wäwänin aianinichsit. 


\section{ANAMIHÄU PEME.}

K.-Hawäno tä maiene ene Anamihäu Peme?

N.-Kaiäz wesakesit kä, nä-känekon asau nepäk.

K.-Wäki tä maiene wesakesit Anamihäu Peme?

N.-1) Mawau kä o jäzetonechson kischekatäwon, mawau miniu enekoch o päzetonon kaies wanänechtach kisehekatäwon.

2) Mäz Hawätok o sawänechzekon miniu menekoseu waiesukesit, sinawaneu asau kotakänechtach ächpez wesakesit.

3) Sochkitähäskawau miniu waiesakesit, asau sakozehekot maze hawätokon.

4) Naianekotochkin miniu waiesakesit ioch mächnoiu Anamihäu Peme, kespin Mäz Hawätok enänechtach.

K.-Ta tä pos äsetot weiak asau mächno otachpenach Anamihäu Peme?

N.-Wäwänin kä pos paketchekäu, achpäniu miniu Mäz Hawätokon pos achpänemo. 
K.—Wäki tä Mächkotächkoniäu wä menazin Anamihäu Peme waiesakesinit oskechseko, ochtawake, otchiase, otone, onächke, osete miniu?

N.-Kit àtoch kä kiskichsekonoa, kichtawakenawanon, ki tchiasenawon, kitonenawon, mawau kä kenoa, as päzetaiach, ene tä Mächkotächkoniäu wä anamihätawazin waicsakesinit, as menazin Anamilhäu Peme, asan sawänemekot Mäz Hawätokon, asau kischamakot mawau kaiesis päzetot as kes maze atok oskechsekon, ochtawakon, mawau miniu weau.

K. - Ta nä tachnäno weiak pos waichkichtok asau otachpenach Anamihäu Peme?

N.-Nekotono kä nesik weiak wesakesit, ene nesik nekotono os pos mene Anamihäu Peme. Inänit tä, misik tä käz wesakesit, ene tä misik os pos wichkichtok os pos otachpenach Anamihäu Peme.

K. - Iachpez maze esetau as paketenazin weiak as nepäk konomächtchiu asau otachpenach Anamihäu Peme?

N.-Kätiu mäz päzetau eno. Pon, pon 
nekotoch paketenin weiak asau nejäk, konomächtchiu asau niakot Mächkotächkoniäu. Nohekon ene peponakesit nitchion käz wesakesit awech natomin Mächkotächkoniäu, asau paketcheket nitchion, asau otachpinach miniu Anamihäu Peme. Poz käz wanau it Mächkotächkoniäu, poz käz käsik, konopoz kimewan, naskat awech natomin Mächkotächkoniäu, Mäz Hawätok tä kinau mächno totak nekotäs kesekoch.

\section{MÄCHKOTÄCHKONIÄWIN.}

K.-Hawäne tä maiene ene Mächkotächkoniäwin?

N.-Enoch kä nätawänechtach asau katäu Mächkotächkoniäwit.

K.-Hawäne tä waichkichtok as mikit Mächkotächkoniäwin?

N.-Mäz Mächkotächkoniäu kä nesik.

K.-Wäki tä äsis minichtoa Mächkotächkoniäwin wätachpinachkoa?

N.-Ene kä äsis minichtoa Mäz Hawä- 
tok o sawänechzckon, asau wichkichtokoa asau paketänemawatoa Jesus Weau as mäk Mäz Anamihan, kwaiachk miniu asau wichtamawikitoa Jesus ot Äsechzekan, asau kisihamawikitoa miniu päzetonon päketchekachkin, mawau miniu wäwänin asau isitaloa, Mächkotächkoniä wak äsis natawänichtakositoa asau isichziketoa.

K.-Ta misik äsikimakach Mächkntächkoniäwin?

N.-Akiko wätachpinachkoa Mächkotächkoniäwin, kon o wichkichtonowawon Anamihäu Wikichtwon asau otachpinachkoa. Alkiko tä wätachpinachkoa Anamihäu Wikichtwon, kon pos o wichkichtonowawon Mächkotächkoäwin os pos otachpinachkoa, au äz wikimatoa metämochson.

\section{ANAMIHÄU WIKICHTWON.}

K.-Wäki tä äsis minichtoa Anämihäu Wikichtwon wätachpinachkoa?

N.-Ene kä äsis minichtoa änamihäu 
nepawitoa Mäz Hawätok o sawänechzckon, asau tapanititoa, asau mächno isikitoa, asau mächno kisikihatoa onitchionechsowawon, kwaiachk miniu asau kächkenohamawatoa Anamihan.

K.-Hawäne tä waichkichtok asau wikichtahazin änamihatoa?

N.-Mächkotächkoniäu kä nesik.

K.-Wäki tä pos äsitatoa änamihatoa konomächtchiu asau anamihäu népawitoa?

N.-Pos aninichsowak kä, wäwänin miniu pos paketchckewak konomächtchiu asau anamihäu nipawitoa.

K.-Kakik tä asau wikichtitoa inänichtakosiwakit änamihäu nipawitoa?

N.-Au äz pematesitoa kä asau wikichtitoa inänichtakosewak anamihäu ṇepawitoa; käz maze esetawak kespin as pachkähititoa, as pakenititoa. Jachpez matät ene.

Kespin tä änamihatoa nasächkawatoa kaiänit kakichkimewäwon, konemau miniu tepachkonikäwon asau nepawitoa, käz päzetawak. Enoch nesik Mäz Mächko1ächkoniäu pos waichkichtok, asau ki- 
schamawazin o ] äzetor. Jachpez matät ene.

K.-Hawäne tä kaies osechrok Anamihäu Wikichtwon?

N.-Mäz Hawätok kä kes osechtok Anamihäu Wikichtwon.

K.-Wäki tä Mäz Hawätok kaies io osechtok Wikichtwon?

N.-1) Opäsik asau manätoa, achpäniu miniu asau tanäsitoa pämatesitua achkihe.

2) Wäwänin asau mazikihatoa nitchianon, asau tapanatoa Täpänechzekänit -Mäz Hawätokon, asau kohnatoa, asau anochkitawatoa miniu.

3) Ene neu miniu kaies io osechzekatäk Anamihäu Wikichtwon, kon asau päsikoatesitoa änamihatoa, asau pinisitoa tä achpäniu äsis mininechtach Täpänechzokät.

4) Asau tapanititoa, asau witochkatitoa, asau mächno cchpänanetitoa minir, kespin wesakesit nekot konemau miniu koskänechtach. 


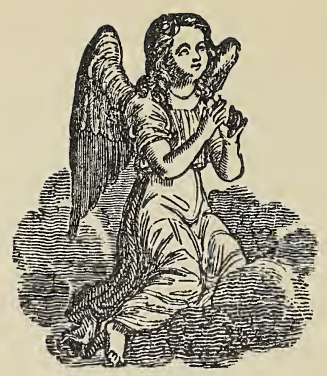

IV.

\section{ANAMIHAN.}

K.-Wäki tä Anamihan?

N.-Weiak kä Mäz Hawätokon as keketotawazin as mächkawänemazin miniu, ene kä ene anamihan ätamä.

K.-Ene tä neu äsis weskewach as kikiti nesik änamihachkin?

N.-Kon kä isis weskewaton as kikiti nesik änamihachkin; pos nanakatawänechtoin kä ächpez anamiha.

K.-Jachpez 1ä weskewatoat anamihan? 
N.-Jachpez kä wcskewat anamihan; iachpez enapatot ; kätin sawänechtakoseu kwaiachk änamihat; Mäz Hawätokon tapanik, nähe sawänemik. Kat änamihat tä kon o tapanekonon Mäz Hawätokon. K.-Ta ene anamihan opäsik waieskewach?

N.-Ene kä anamihan: "Nochnenau keseknch äpeon" opäsik waieskewach, wenä kä Jesus kaies osechtok ene anamihan.

K.-Ta ätamä cne anamihan?

N.-Ene kä etámä: "Nochnenau kesekoch äpeon.

1) Nas tä kat käz achpechtänechton $K i$ Wichswon.

2) Nas tä kat pimakat kit okemawin.

3) Änänechtamon nas tä kat esekemakot, tepach kesckoch ene miniu achkihe.

4) Mereach iochpe as kesekach ne pachkishikanemenau tachnäno kesekach.

5) Ponikitätaweach miniu kaiesis nächkehekäon äsis ponikitätawakichtoa kaiesis nächkihiamechtoa. 
108

6) Pon miniu ishiaseach kakiztipänichtoane.

7) Miakonamoweach tä mäte. Amen. K.-Ta enekoch äsis natotamawake Mäz Hawätok ene anamihani: "Nochnenau kesekoch äpeon?"

N.-Nohckon kä kit äsis natotamowonau.

K.-Ta ätamä nätom ene anamihan?

N._Ene kä nätom etàmä: "Nochnenau kesekoch äpeon.

K.-Wäki tä Mäz Hawätokwä is wichsit Nochnenau?

N.-Ene kä wä is wechnake Nochnenau, wenä kä kikes menekonau pematesin, mawau miniu käkoch ki menekonau eneko ätawach.

K.-Wäki tä nätom äsis natotamawake Mäz Hawätok ene anamihani?

N.-Ene kä nätom äsis natotamawake: "Nas tä kat käz achpechtänechton Ki Wichswon."

K.-Wäki tä äsis natotamawake Mäz Hawätok ene as ea?

N.-Ene kä äsis natotamawake, asau 
sawänemazin mamazetawon, mawau asau kächkenakot, asau tapanekot, wäwänin miniu asau anochkitakot.

K.-Wäki tä nishino äsis natotamawake Mäz Hawätok ene anamihani?

N._Ene kä nishino äsis natotamawake : "Nas tä kat pimakat kit okemawin."

K.-Wäki tä äsis natotamawake $M a ̈ z$ Hawätok ene as ea?

N.-Ene kä äsis natotamawake, asau sawänemena kakik asau apet kitäheno; kes nepäiach tä, ot okemawine kesekoch asau piatäwehena.

K.-Wäki tä nänino äsis natotamawake Mäz Hawätok ene anamihani?

N.-Ene kä nänino äsis natotamawake: "Änänechtamon nas tä kit esckemakat tepach kesekoch, ene miniu achkihe."

K.-Wäki tä äsis natotamawake $M \ddot{a z}$ Hawätok ene as ea?

N.-Ene kä äsis natotamawake Mäz Hawätok, asau sawänemena asau isis menenach sochkänichtamoan, asau achpäniu wäwänin papamächtawake ios achkihe; kaiäz achpechtänetakositoa kesckoch äpi- 
toa, asäniwak mıniu äsis papamächtawatoa kesekoch ene asau isis papamächtawake miniu kinach ap ios achkihe.

K.-Wäki tä niu eno äsis natotamawake Mäz Hawätok ene anamihani?

N.-Ene kä niu eno äsis natotamawake : "Meseach iochpe as kesekach ne pachkishikanemenau, tachnäno kesekach.”

K.-Wäki 1ä äsis natotamawake Mäz Hawätok ene as ea?

N.-Ene kä äsis natotamawake, asau isis menenach tachnäno kesekach, au ioch pematesit ki tätchiakonau, miniu tä keowonau au ioch pemateseach.

K.-Wäki tä wä käz enapazechtok ki tätchiakonau au ioch pematesit?

N.-Ene kä wä käz enapazechtok ki tätchiakonau: Mäz Hawätok o sawänechzekan, Mäz Hawätok miniu o kikitwon, käz Sawänechtakosin miniu.

K.-Wäki tä nianon äsis natotamawake Mäz Hawätok ene anamihani?

N.-Ene kä nianon äsis natotamawake : "Ponikitätaweach miniu kaiesis nächkihikäon, äsis ponikitätawakichtoa kaiesis nächkihiamächtoa." 
K.-Wäki tä äsis natotamawake Mäz Hawätok ene as ea?

N.-Ene kä äsis natotamawake asau isis ponikitätona as kes pazotaiach, äsis ponikitätawakichtoa mawau kez pematesinawak kaies nächkihinachkoa.

K.-Pos ki ponikitätakuna tä Mäz Hawätok kaies päzetaiach, kespin kat ponikitätawakichtoa kaies nächkihinachkoa?

N.-Kon pos ki ponikitätakoninawon; kachneu nesik kes ponikitätawakichtoa kaies näch kihinachkoa, ene kachneu miniu wenach Mäz Hawätok asau ponikitätona.

K.-Wäki tä nekotoasita neno äsis natotamawake Mäz Hawätok ene anamihani?

N.-Ene kä nekotoasita neno äsis natotamawake: "Pon miniu ishiaseach kakiztepänichtoane."

K.-Wäki tä äsis natotamawake Mäz Hawätok ene as ea?

N.-Ene kä äsis natotamawake, asau sochkitähäskonau, asau menenach miniu tatachkesin, papik asau paketama, asau sechkatama miniu maze inänichtamoan wätächkoiachlkin, asau nochkechtawach miniu mawau maze esekin. 
K.-Wäki tä nohckon tachnäno äsis natotamawake Mäz Hawätok ene anamihani?

N.-Ene kä äsis nohekon tachnäno äsis natotamawake: "Miakonamoweach tä mäte." Amen.

K.-Wäki tä äsis natotamawake Mäz Hawätok ene as ea?

N.-Ene kä äsis natotamawake, asau kanawehena, käkoch mätächkin kat asau otächnekoiach keionoa, ki tätchiakonoa miniu; mämik tä asau kanawchena, kon nekotoch asau maze esetaiach, kakik iskotia kat asau papechzenach kes anich pemateseach achkihe.

K.-Kaies ani, etámä ene anamihan "Nochnenau," wäki tä misik anamihan ätoa änamihatoa?

N.-Ene kä ene anamihan: "Kit anomächkon Mani" ätoa. Ene as mamiachtomake käz Marie ene anamihani, asau keketotamonach.

K.-Ta ätamä ene anamihan?

N.-."Kit anomächkon Marie maioskinaniläion sawänechzckon, Täpänächzc- 
kät ki witchiak. Ki käz achpechtänetakosim ächtachsitoa metämochsok, käz achpechtänetakoseu miniu kaies kikäskawat Jesus. Käz Marie, Wäkiachseme Mäz Hawätok, keketotamaweach as päzetaiach, iochpe misik tä tipachikone as nepäiach. Amen."

K.-Hawäne enoch Käz Mani?

N.-Mäz Hawätok Okison ot okiachsemau käz Mario miniu kinach kit okiachsemonau. Konau kä onitchionächsen käz Maric, konau miniu kekachkoweu. Waieskusinit Hawätokon kä kes pis otächnik, Mäz Hawätok o tatachkesin kes pis okoanäskak, ene tä kaies io onitchianächsit käz Marie, kon tä nekotoch inäniwon o kes kächkenawanon.

K.-Weskewatoat ene as käz enapazechtok miniu, asau mamiachtomake käz Marie?

N.-Käz weskewat kä ene as käz enapazechtok miniu, achpäniu miniu asan mamiachtomake käz Mani. Kit änänemekonau Täpänechzekät asau menazehake kaickachkoit käz Mani. Pakichsänemin 


\section{4}

enoch käz Mani asau kanawche, mämik natotamowin penetähän, tapachnenichswon, waieskewach miniu nepän.

K.-Weskewatoat ene as käz enapazechtok miniu asau mamiachtomakichtoa käz Asäniwak, mawau miniu kaiäz achpechtänetakositoa kesekoch äpitoa?

N.-Käz weskewat kä ene as käz enapazechtok, achpäniu asau keketotamonachkoa kesekoch.

K.-Enit tä nou tepa äsis mamiachtomakichtoa kaiäz achpechtänetakositoa, kesekoch äpitoa, äsis mamiachtomake Mäz Hawätok?

N.-Kon pachpis tepa kit äsis mamiachtomaninawon kaiäz achpichtänitakositoa kesekoch äpitoa, äsis natotamawake Mäz Hawätok. Kit äsis natotamawónau kä wenach Mäz Hawätok, asau menenach mesäs käkoch au isis átawach ; kaiäz achpcchtänetakositoa tä kesekoch äpitoa kit äsis mamiachtomonawak nesik, asau keketotamonachkoa, Mäz Hawätok asau menenach au isis äwäiach. 
K.-Kächkinamokit tä käz achpechtänetakositoa kesekoch äpitoa kaieketotawakichtoawin?

N.-Kächkenamok kä kaieketotawakichtoawin, Mäz Hawätok io kächkenamok. Kes hewa kä Jesus : Käz onanekosewak kesekoch aitoa, kespin weiak mäze esekit ios achkihe kochketat tä asau aninichsit asau mächno esekit. Kächkenamok kesckoch äpitoa, äsikitoa pematesitoa achkihe. 
116

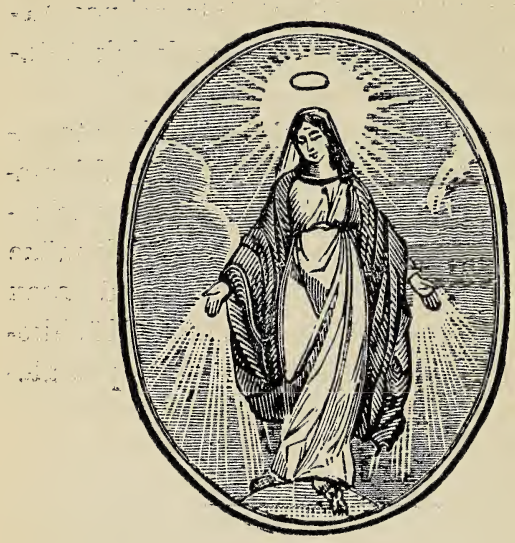

V.

\section{PÄZETONON.}

K.-Wäki tä päzeton?

N.-Ene kä ene päzeton, kespin weiak kat äsetot, Mäz Hawätok äsis aiakoamechnesit; konopoz miniu äsetot, Mäz Hawätok äsis kinoawikit. 
K:-Ta ächtachnä päzeton?

N.-Nish kä: ene kä päzeton pis kikeochtateseach, Adam, Eva miniu kaiesis -päzetatoa, ene tä ene paitawach as ochtateseach; enechpe tä miniu päzetonon, kina nap äsis päzetaiach.

K.-Ta tä ächtachnächkin äsis päzetaiach?

N.-Niu kä : as maze inänechtamach, as maze kikitiach, as maze esetaiach, neanekotochkin miniu aiano mächkamachkin os pos mächno esetaiach, kat as maiächno esetaiach tä.

K.-Mawau tä päzetonon tepa achpichtänichtakwotonit?

N.-Kon kä mawau päzetonon.tepa achpichtänichtakwoton; anä kä mäz päze-ton, anä tä päzetonechson.

K.-Ta äsis kitämakehekäiach mäz päzeton?

N.-Kespin kä as mäz päzetaiach, ki iachpez panazechtomenau Mäz Hawätok o sawänechzekan ; ene miniu äsis wichkoazichtoaseach, anamachkiach kakik iskotia asau achpakinikäiach. Ene tä ene 


\section{8}

wäwänin pos kätau io kanawechtawach keonawon, asau sechkatamach mawau mäz päzetonon.

K.-Ta äsis kitämakehekäiach päzetonechson?

N.-Kespin kä mänawaz nesik päzctaiach, kon kätin iachpez mawau Mäz Hawätok o sawanechzekon ki panazechtoninawon, mänawaz tä ano ki panazechtomenau; ene tä au io sechkatamach miniu wenach päzetonechsä, encko äsis wichkichtawach.

K.-Pos ki wichkichtomenau tä, asau sechkatamach päzetonon, Mäz Hawätok kat wetochkona?

N.-Kon pos ki wichkichtoninawon asau sechkatamach päzetonon, Mäz Hawätok kat wetochkona; ene tä neanekctochkin pos wä mamiachtomake Mäz Hawätok asau wetochkona, mawau asau sechkatamach päzetonon.

K. -Ta ächtachnächkin mamach päzctonon naikanänichtakochkin?

N.-Nohekon kä mamach päzetonon naikanänichtakochkin : 
1) Mamenatesin.

2) Positchion.

3) Päsikoatesin.

4) Kishiawänichtwon.

5) Nepatesin.

6) Nächkosin.

7) Tatakazichkwon.

K.-Wäki tä wä is wechtamä anino päzetonon: Mänätamekämakachkin päzetonon.

N._Ene kä wä is wechtamä mänätamekämakachlin päzetonon, ene enis wächzechne mäse päzetonon; tepachneu otchipä mäse wä sákikä mätikoachsä, ene tepa äsikimakach.

K.-Hawäne enoch mämenatesit?

N.-Eno mämenatesit osam nätawänechtach as katäu käz achpechtesit, as katäu menätamechket; osam miniu täpàtach weau, täpachnänemazin tä wez pematesewon.

K.-Menätamechkemakat tä ene päzeton mamenatesin?

N.-Menätamechkemakat kä ene päzeton mamenatesin; Mäz Hawätok anamachkiach kakik iskotia kes achpakenäu asäniwon kaies mamenatesinit. 
K.-Hawäne enoch paiositchit?

N.-Eno kä paiositchit, osam mäninimazin sonianon, osam miniu mäninechtach mesas käkoch tanàn ios achkihe ächtakik.

K.-Menätamechkemakat tä ene päzoton positchion?

N.-Menätamechkemakat kä ene päzeton positchion. Ene äsis näme Mäz Hawätok o masénachekone: "Positchion ene enis wä sàkekä mäse päzetonon.

K.-Ta nä tä äsis päzetot paiositchit?

N.-Waiäsemäu kä wez pematesewon äsis wichkichtok; kon miniu nekotoch weon o sawänemanon.

K.-Ta nä ächtachnä äsis päzetot päsikoatesit?

N.-Näniu kä: maze enänechtamächkin, mäzo kikitichkin, mäzo esetachkin miniu.

K.-Menätarnechlemakat tä ene päzeton päsikoatesin?

N.-Menätamechkemakat kä ene päzeton päsikoatesin. Ene kä nekotäs kaiesis wenosach Mäz Hawätok nish minikanon, Sodoma, Gomova miniu äs weehtekin, as 
kes păsikoaz isikitoa enis kaies tanachkitoa. Ene tä kakik iskotia asau achpakenazin mawau päsikoaz isikitoa, kespin kon iazichtokoa o pämatesinowawon.

K.-Hawäne enoch käshiawänechzeküt?

N.-Enoch kä näch kishiawänechzekät, käskänechtach, nächkosit mıniu, wez pematesewon käkoch äsis sawänechtakosinitchin; wänanikinechtach tä, wez pema tesewon käkoch äsis panatesinitchin.

K.-Menätamechkemakat tä ene päzeton kishiawänichtwon?

$\mathrm{N}$--Menätamechkemakat kä ene päze ton kishiawänichtwon; wenä kä maze hawätok anamachkiach äpit, kes pitau kishiawänichtwon ios achkihe. Naiäwa zin kä nätom pematesewon, A^dam Ewa miniu, äsis sawänecbtakosinit käz monachekone, kes pis ishiu achkihe, kinopik kes pis ishinakihäso, as kes pis päzetachnazin tä nätom mamazetawon, ene tä as kes käz kitämakehazin, ene tä as kes mi ninechtach.

K.-Ta tä äsis päzetot käshiawänech。 zekät? 
N.-Achpäniu kä mekoskazehäu nächkosetawäu miniu wez pematesewon achpäniu miniu tasemäu.

K.-Hawäne enoch näpatesit?

N.-Eno kä näpatesit, osam näch mitchichsit, osam miniu näch menäk.

K.-Menätamechkemakat tä ene päzeton nipatesin?

N.-Menätamächkemakat kä ene päzcton nipatesin; ene kä ene mämik mäz päzeton, kiwaskipion. Ene äsis näme Maze Hawätok o masenachekone: Näch kewaskipitoa kon nekotoch kesekoch onau ishianowawon, kakik iskotia au wenosowak, kespin kon iazichtokoa o pematesinowawon.

K.-Ta nä äsis päzetot näpatesit?

N.-Osam kä maitchichsichkin, osam miniu mänächkin, ene as wesakesechtok weowawon, kiłäkeheso miniu. Kaiwaskipit anoz maze keketo, anoz miniu maze esctau; käz nächkehäu Mäz Hawätokon, wäwepoz miniu maze echpänanäu wez pematesewon. 
K.-Hawäne enoch näch nächkosit?

N.-Eno kä näch nächkosit, nätonächha as katäu asechtawahazin wez pematesewon, käkoch äsis nächkehckazin.

K.-Menätamechkemakat tä ene päzeton nächkosin?

N.-Menätamechkemakat kä ene päzeton nächkosin. Isis aiakoamemäu kä Jesus änamihanit asau tapanititoa, asau ponikitätatitoa miniu käkoch kaies nächkehititoawin. Kon Mäz Hawätok pos o ponikitätawanon päzetonit, konomächtchiu as ponikitätawazin wez pematesewon kaies nächkehekozin.

K.-Maze esetawakit tä wänitchianächsitoa, kespin mäse kikitotawatoa säsewahatoa miniu onitchionechsowawon, käkoch mäze as esetanitchin.

N.-Kon kä maze ot äsetanowawon wänitchionächsitoa, kespirı mäse kikitotawatoa säsewahatoa miniu onitchionächaowawon, käkoch mäze as esetanitchin. Mär·hno esetawak kä wäwänin as säsewahatoa; kon tä osam mäse as pakamatoa, kon miniu wene; kon miniu konau kaics maze enatoa. 
K.-Hawâne eno taiatakazichkit?

N.-Enoch kä taiatakazichkit, wäwänin. kon as anochkit au io pematesit; enoch miniu, wäwänin kon asau anamihat, kon miniu as äsetot, pos kaies esetot, asau wichkichtok kakik onanekosin kesekoch.

K.-Menätamechkemakat ene päzeton tatakazichkion?

N.-Menätamechkemakat kä ene päzeton tatakazichkion.

K.-Misik tä anä àtäwon mäz päzetonon?

N.—Misik kä nekotoasita atäwon mäz päzetonon, ene kä päzetonon wä nächkehe Waieskesit Hawätok. Enø kä äsis päzetot:

1) Osam weiak achpänimit Mäz Hawätok äsis kishiatesinit. (Kespin weiak ene esekit, enänechtam: Iachpez Mäz Hawätok kishiateseu ; ano päzetaion, pochz kesekoch nenau otachpenik kes ani pemateseon achkihe. Ene as enänechtach, ene tä wächzetau päzetone tase pematesit.)

2) Osam mänawaz weiak achpänimit Mäz Hawätokon aiano kishiatesinit. (Kespin weiak ene esekit, enänechtam. "Kon 
nekotoch Mäz Hawätok nenau ponikitätakonon, kon nekotoch kesekoch nenau otachpenekonon. Ene as enänechtach, ene tä kon nekotoch asau wichkoazichtoasit asau aninichsit, asau iazechtok o pämatesin; enänechtam kä; Kon pochz nekotoch nenau wichkichtoasenon kakik sawänechtakosin kesekoch.)

3) Wächzetau weiak kenochtach onamuon, aiano (as) kächkenach as onamimakach. (Kespin weiak ene esekit, wächzetau mekàtam anamihäu onamuon, aiano kächkenach otähe äsis weskewach ene onamuon.)

4) Weiak as kakawänemazin wez pematesewon, Mäz Hawätok o sawänechzekan io kakawänemazin. (Kespin weiak ene esekit, ene tä as näwazin wez pematesewon as tanäsenit Mäz Hawätok o sawänechzekane, nächkänemäu; kon o mäninechtonon as näwazin wez pematesewon äsis sawänechtakosinit Mäz Hawätok o sawänechzekane.)

5)Weiak wächzetau päzetone tase pematesit. (Kespin weiak ene esekit, kon ne- 
kotoch of änänechtonon asau iazechtok o pematesin, kon miniu anamihäu kakichkotakan o papamänechtonon; iachpez kesänechtam achpäniu asau esetot wenach as änänechtach, aiano mazo escke.)

b) Weiak kon nekotoch aianinichsit nanas asau nepäk. (Kespin weiak ene esekit, kon nekotoch o nasächkawanon Mächkotächkoniäwon asau paketcheket; kon miniu otähe ot aninichsinon; kon o papamänechtonon aninichswon kotakiheswon miniu, ächpez mininichtach päzeton, nanas päzetone asau tachpänät.

K. - Wäki tä Jesus kaies eta anino päzetanon io?

N.-Kes hewa kä: Anino päzetonon wäch nächkche Waieskesit Hawätok, kon nekotoch pos o kisehekatäwonon, kon ios achkihe, kon miniu enis kes ani nepäk.

K.-Wäki tä kätau eta Jesus?

N.-Ene kä wä enazin: Kespin weiak anino päzetonon kikäskach, kon nekotoch wäwänin ot aninichsinon, achpäniu mäz päzetone tase pemateseu, mäz päzetone miniu tachpänäu; ene tä kätin kon nekotoch os pos kisehekatäkin o päzetonon. 
Kespin tä weiak kwaiachk aninichsit, ponechtok miniu o maze pematesin, pos kisehamawäu, pochz kaies iachpez maze esekit.

Kon kä Mäz Hawätok o natawänemanon maze esekenit päzetone asau tachpänät; natawänemäu kä asau tachpänät natawänemäu kä asau aninichsinit, asau iazechtonik o maze pämatesin, ene tä kakik kesekoch asau pematesinit.

K.-Misik tä anä mäz päzetonon atäwanit?

N.-Misik kä niu atäwon mamach päzetonon an io ohohemakach kesekoch kat asau wasichtawahitich.

K.-Wäki wä etamä: Kesekoch ohohemakaton anino päzetonon?

N.-Ene kä wä etamä : Mäz Hawätok - masenachekone kä asachzekatäu kaies eta Mäz Hawätok echpe Kain kaies nähnazin ochsemächson Abelon; kes hewa kä : "Abel o mächkom kaies sekinikatäk achkihe, ohohemakat kesekoch, asau asechtawahake enoch kaies nähsewät." 
K.-Akechtä anino niu päzetonon?

N.-1) Weiak wächzetau as nähnazin wez pematesewon.

2) Sodoma o päzeton. (Ene kä nekot päsikoaz esekin.)

3) Weiak maze echpänanazin kätemakesinit, saiekawenit, kaiewesinit miniu.

4) Weiak kat kwaiachk as tepahamawazin kaies anonazin asau anochkit.

K.-Enit tä nesik ene pos wäch tepachkone änamihat, wenach tepenau eneko mäze as esetot?

N.-Kon wenach tepenau nesik eneko mäze as esetot pos io o tepachkonanon änamihat, ene neu miniu ene pos wä tepachkone, eneko as mäze echpänanazin, as mäze kächkenohamawazin miniu wez pematesewon.

K.-Ta ächtachnä ene äsis päzetahazin weiak wez pematesewon?

N.-Sakäu tachnäno kä: ene kä päzetonon kaï̈nesewak o päzetonowawon ätamä.

1) Weiak as kekomazin asau päzetot.

2) Weiak as aiakoamemazin asau päzetot. 
3) As mininechtamä weiak as päzetanit.

4) W'eiak as kakachsächta nanas asau päzetot.

5) As minuazeme weiak as päzetot.

6) As kiane weiak kaies päzetot.

7) As wetochko weiak as päzetanit.

8) Kat as aianächne weiak, kespin miniu kat säsewako as päzetanit.

9) As natamo, as mächno echpänane miniu weiak as päzetot.

K.-Enit tä neu äsis täpechnä änamihat asau sechkatach nesik mawau päzetonon?

N.-Kon isis täpechnenon änamihat asau sechkatach nesik mawau päzetonon; ene kä äsis natawänechtakositoa änamihatoa asau mächno esetatoa eneko äsis wichkichtokoa.

K.-Pos wichkichtau tä weiak asau mächno esetot, wenach neu änänechtach?

N.-Kon weiak pos o wichkichtonon os pos mächno esetot, os pos mächno esekit miniu, wenach neu änänechtach; Mäz Hawätok ki menekonau o sawänechzekon, ene tä ene nesik wä wichkichtawach asau 


\section{0}

mächno inänechtamach, os pos mächno esekeach miniu: ene tä änamihat ach niu pos wä mamiachtomazin Mäz Hawätokon asau menekot sawänechzckan.

K.-Ta tä anino opäsik wäieskewach änamihat $o$ mächno esetanon.

N.-Näninon kä käz mächno esetanon :

1) Anamihan.

2) Mesachkatawän.

3) Sawänechzekan.

K.-Ta ächtachnächkin mächno esetanon maikatimakachkin mamach päzetonon.

N.-Nohekon kä :

1) Tapachnenichswon mikatimakat mamenatesin.

2) Käshiatesin mikatimakat positchion.

3) Penctähän mikatimakat päsikoatesin.

4) Tapanitwon mikatimakat kishiawänichtwon.

5) Tepamänimoan mikatimakat nipate$\sin$.

6) Nawaneu esekin mikatimakat nächkosin.

7) Nänepewin mikatimakat tatakazichkion. 
K.-Ta ächtachnä anino mächno esetanon, äsis mächno echpänane wez pematesemau äsis oweawit?

N.-Nohekon kä anino mächno esechzekanon:

1) As achsamichtoa pachkatätoa.

2) A.s ménahichtoa paichkapakitoa.

3) As pichtikanichtoa as weke kaiänesitoa (päpamochnetoa.)

4) As akihichtoa kätemakesitoa.

5) As papam wapamichtoa waicsakesitoa.

6) As tipahochtoa tächkonichtoa, (asau anich kotakihichtoa.)

7) As pakitänimichtৎa näpikoa.

K.-Wäki kaies enazin anino mächno esechzekenon io?

N.-Kes hewa kä, tepachkonikäu kesekach asau mächkawänechtach anino mächno esetanon, ene tä asau eta: "Eneko kaies echpänanekoa kez pematesewak, nenach neu kaies echpänaseäk." Ene tä kakik pematesine asau pichtiketoa akiko kaies mächno echpänanatoa arhkihe.

K.-Misik tä átäwanit mächno esetanon? 
N.-Misik kä nohekon mächno esechzekanon äsis mächno echpänane weiak äsis otätchiakit.

1) Wäwänin as aninime päzitatoa.

2) As käuhkenohamochtoa kon kälkoch kächkinachkoa.

3) As mächno kakichkimichtoa kon kächkinachkoa au esetatoa.

4) As nähekazimichtoa kaiäz kaskänichtachkoa.

5) As mächno otachpenamochtoa kat maiächno totawikitoa.

6) As ponikitätochkoa kaies nächkihikitoa.

7) As keketotamochtoa pämatesitoa näpikoa miniu.

K.-Ta tä änamihat au isis tapanazin wez pematesewon?

N.-Äsis tapanisit kä pos isis tapanäu mawau wez pematesewon. Äsis mininechtach weiak asau echpänane, ene pos echpänanäu miniu wenach nap wez pematesewon; kat äsis mininechtach tä weiak asau echpänane, kon miniu wenach pos ot echpänananon wez pematesewon. 
K.--Mininechtamot tä Jesus, änamihat asau mächno echpänanazin wez pematesewon?

N.- Jachpez kä mininechtam; io kä kaies eta: "Eneko au echpänanazin weiak wez pematesewon, nenä neu au echpänanäsit." sinon?

K.-Ta ächtachnächkin sawänechtako-

N.-Shuasik kä :

1) Sawänechtakosewak kätemakesitoa otätchiakoa, akiko kä wätachpinichkoa okemawin kesekoch.

2) Sawänechtakosewak maiächno esetähätoa akiko kä achkäu au tepänichtachkoa.

3) Sawänechtakosewak kaskänichtachkoa as kes maze äsitatoa, akiko kä au mininichtachkoa.

4) Sawänechtakosewak pachkatäton, paichkepakitoa miniu kwaiachk pematesin, akiko kä au täpinachkoa.

5) Sawänechtakosewak nähe sawänechzekätoa, akiko kä au sawänimichtoa.

6) Sawänechtakosewak penetähätoa, akiko kä Mäz Hawätokon au näwätoa. 


\section{4}

7) Sawänechtakosewak nawaneu isikitoa, akiko kä Mäz Hawätok o nitchionechson au inichtoa.

8) Sawänechtakosewak kwaiach Anamihan wä kotakihichtoa, akiko kä wätachpinichkoa okemawin kesekoch.

K.-Ta ächtachnä minuazimonon kakichkotakanon?

N.-Näninon kä :

1) Wächzetau neu as mininechtamä as kitämakese.

2) Kakik penesin, penetahän äsis oweawit äsis otätchiakit miniu.

3) Achpäniu miniu asau pächtawatoa änamihatoa naikanisitoa.

K.-Ta ächtachnächkin anino aiatchkoa au pis takikin, echpe asau mäzechne pämatesin?

N.-Niu enon kä :

1) Nepän.

2) Tepachkonikon.

3) Anamachkiach.

4) Kesekoch. 


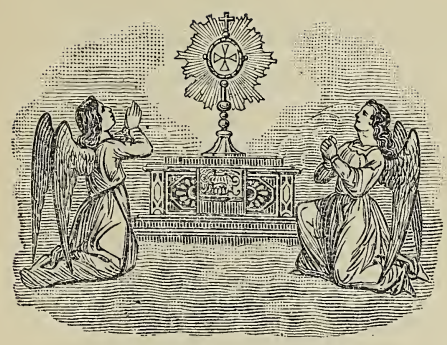

\section{MÄZ ANAMIHAN.}

Mächkotächknniäu:-In nomine Patris, et Filii, et Spiritus Sancti, Amen. Introibo ad altare Dei.

Änochkitawazin :-Ad Doum, qui laetificat juventutem micam.

Mächk:-Judica me Deus et discerne causam meam de gente non sancta: ab homine iniquo et doloso erue me.

Änochk :-Quia tu es, Dous, fortitudo mea: quare me repulisti, et quare tristis incedo dum affligit me inimicus? 
136

Mächk:-Emitte lucein tuam et veritatem tuam: ipsa me deduxerunt et adduxerunt in montem sanctum tuum, et in tabernacula tua.

Änochk :-Et introibo ad altare Dei : ad Deum, qui, laetificat juventutem meam.

Mächk:-Confitebor tibi in cithara Deus, Deus meus: quare tristis es anima mea, et quare conturbas me?

Änochk :-Spera in Dco, quoniam adhuc confitebor illi: salutare vultus mei, et Deus meus.

Mächk:-Gloria Patri, et Filio, et Spiritui Sancto.

Änochk:-Sicut erat in principio, et nunc, et semper, et in saecula saeculorum. Amen.

Mächk :-Introibo ad altare Dei.

Änochk :-Ad Doum, qui lactificat juventutem meam.

Mächk:-Adjutorium nostrum in nomine Domini.

Änochk:-Qui fecit coelum et terram. Mächk:-Confiteor Dro omnipotenti. 
Änochk:-Misereatur tui omnipotens Deus, et dimissis peccatis tuis, perducat te ad vitam aeternam.

Mächk:-Amen.

Änochk:-Confiteor Deo omnipotenti beatae Mariae semper Virgini, beato Michaeli Archangelo, beato Joanni Baptistae, sanctis Apostolis Petro et Paulo, omnibus Sanctis, et tibi, pater quia peccavi nimis cogitatitione, verbo et opere: mea culpa, mea culpa, mea maxima culpa. Ideo precor beatam Mariam semper Virginem, beatum Michaelem Archangelum, beatum Joannem Baptistam, sanctos Apostolos Petrum et Paulum, omnes Sanctos, et te, pater orare pro me ad Dominum Deum nostrum.

Mächk:-Misereatur vestri omnipotens Deus et dimissis peccatis vestris, perducat vos ad vitam aeternam.

Änochk :-Amen.

Mächk:- Indulgentiam, absolutionem et remissionem peccatorum nostrorum tribuat nobis omnipotens et miscricors Dominus.

Änochk :-Amen. 
138

Mächk:-Deus tu conversus vivificabis nos.

Änochk:-Et plebs tua laetabitur in te. Mächk :-Ostende nobis Domine misericordiam tuam.

Änochk :-Et salutare tuum da nobis.

Mächk:-Domine, exaudi orationem meam.

Änochk :-Et clamor meus ad te veniat.

Mächk:-Dominus vobiscum.

Änochk :-Et cum spiritu tuo.

Mächle:-Oremus.....

\section{KYRIE ELEISON.}

Mächk:-Kyrie eleison.

Änochk:-Kyrie eleison.

Mächk:-Kyrie eleison.

Änochk:-Christe eleison.

Mächk:-Christe eleison.

Änochk :-Christe eleison.

Mächk:-Kyrie eleison.

Ånochk :-Kyrie eleison.

Mächk:-Kyrie eleison. 


\section{GLORIA IN EXELSIS DEO.}

Et in terra pax hominibus bonae voluntatis.-Laudamus te.-Benedicimus te.Adoramus te.-Glorificamus te.-Gratias agimus tibi propter magnam gloriam tuam. -Domine Deus, Rex coelestis, Deus Pater omnipotens.-Domine Fili unigenite, Jesu Christe.-Domine Deus, Agnus Dei, Filius Patris.-Qui tollis peccata mundi, miserere nobis.-Qui tollis peceata mundi suscipe deprecationem nostram.-Qui sedes ad dextcram Patris, miserere nobis.-Quoniam tu solus sanctus.-Tu solus Dominus. Tu solus altissimus, Jesu Christe.-Cum Sancto Spiritu, in gloria Dei Patris. Amen.

Mächk:-Dominus vobiscum. Änochk:-Et cum spiritu tuo. Mächk:-Per omnia saecula saeculorum. Änochk:-Amen.

Nawenau nachkotach: Deo gratias.

Mächk:-Dominus vobiscum. Änochk :-Et cum spiritu tuo. Mächk:-Sequentia sancti..... Änochk:-Gloria tibi, Domine. Nawenau nachliotach: Laus tibi Christe. 


\section{CREDO IN UNUM DEUM.}

Patrem omnipotentem, factorem coeli et terrae, visibilium omnium et invisibilium.-Et in unum Dominum, Jesum Christum Filium Dei unigenitum.-Et ex Patre natum ante omnia saecula.-Deum de Deo, lumen de lumine, Deum verum de Deo vero.-Genitum, non factum; consubstantialem Patri, per quem omnia facta sunt.-Qui propter nos homines et propter nostram salutem descendit de coelis.(Otchichtchikoanekopa.) - Et incarnatus. est de Spiritu Sancto ex Maria Virgine, et Homo factus est.-Crucifixus etiam pro nobis, sub Pontio Pilato, passus et sepultus est.-Et resurrexit tertia die secundum Scripturas.-Et ascendit in coelum, sedet ad dexteram Patris.-Et iterum venturus est cum gloria judicare vivos et mortuos; cujus regni non erit finis.-Et in Spiritum Sanctum, Dominum et vivificantem, qui ex Patre Filioque procedit.-Qui cum Patre et Filio simul adoratur et conglorificatur, qui locutus est per Prophetas. Et unam 
sanctam Catholicam et A postolicam Ecclesiam.-Confiteor unum Baptisma in remissionem peccatorum.-Et expecto resurrectionem mortuorum. - Et vitam venturi saeculi. Amen.

Mächk :-Dominus vobiscum.

Änochk : Et cum spiritu tuo.

Mächk :-Orate, fratres......

Änochk:-Suscipiat Dominus sacrificium de manibus tuis ad laudem et gloriam nominis sui, ad utilitatem quoque nostram, totiusque Ecclesiae suae sanctae.

Mächk:-Per omnia saecula saeculorum.

Änochk :-Amen.

Mächk :-Dominus vobiscum.

Änochk :-Et cum spiritu tuo.

Mächk :-Sursum corda.

Änochk :-Habemus ad Dominum.

Mächk:-Gratias agamus Domino Deo. nostro.

Anochk :-Dignum est justum est. 


\section{SA NOTUS.}

Sanctus, - Sanctus, - Sanctus, - Dominus Deus Sabbaoth.-Pleni sunt coeli et terrae gloria tua.-Hosanna in excelsis.Benedictus qui venit in nomine Domini.Hosanna in excelsis.

Mächk:-Per omnia saecula saeculorum. Änochk:-Amen.

Mächk:-Et ne nos inducas in tentationem.

Änochk:-Sed libera nos a malo.

Mächk :-Per omnia saecula saeculor um.

Änochk:-Amen.

Mächl:--Pax Domini sit semper vobis. cum.

Änochk:-Et cum spiritu tuo.

\section{AGNUS DEI.}

Agnus Dei, qui tollis peccata mundi, miserere nobis.

Agnus Dei, qui tollis peccata mundi, miserere nobis.

Agnus Dei, qui tollis peccata mundi, dona nobis pacem. 
Tchepai as anaminätawazin wechta ene:

Agnus Dei, qui tollis peccata mundi, dona eis requiem.

Agnus Dei, qui tollis peccata mundi, dona eis requiem.

Agnus Dei, qui tollis peccata mundi, dona eis requiem sempiternam.

Mächk:-Dominus vobiscum.

Änochk:-Et cum spiritu tuo.

Mächk :-Per omnia saecula saeculorum. Änochk:-Amen.

Mächk:-Dominus vobiscum. Änochk:-Et cum spiritu tuo.

Mächk:-Ite missa est; konopoz Benedicamus Domino.

Änochk:-Deo gratias.

Tchepai as anamihätawazin wechtach ene :

Mächk:-Requiscant in pace.

Änochk:-Amen.

Mächk:- Pater, et Filius, et Spiritus Sanctus.

Änochk :-Amen. 


\section{$1+4$}

Mächk:-Dominus vobiscum. Änochk :-Et cum spiritu tuo. Mächk:-Initium sancti Evangelii...... Änochk:-Gloria tibi Domine. Ánochk :-Deo gratias.

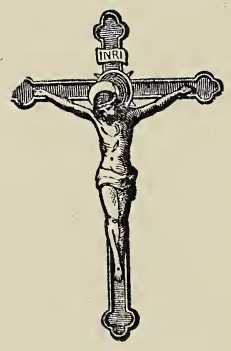




\section{INDEX.}

Angels ..................................... it

Apostles' Creed........................ 7

Baptism................................. 66

Commandments of God............... 49

$$
\text { ". " Church ............ } 59
$$

Confession ................................. 78

Confirmation................................ 71

Extreme Unction ....................... I00

Eucharist .............................. 89

God ..................................... 7

Holy Ghost ............................28, 43

Jesus Christ.............................. 27

Man ... . ..................................... 15

Mary, Hail............................... 112

Mass, Serving at..................... 135

Matrimony............................... 103

Our Father............................... 107

Prayer...................................... 106

Priesthood .................................. 102

Sacraments ................................ 65

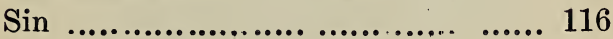

. Sin, Original............................... 19

Six Things of Belief...................... 






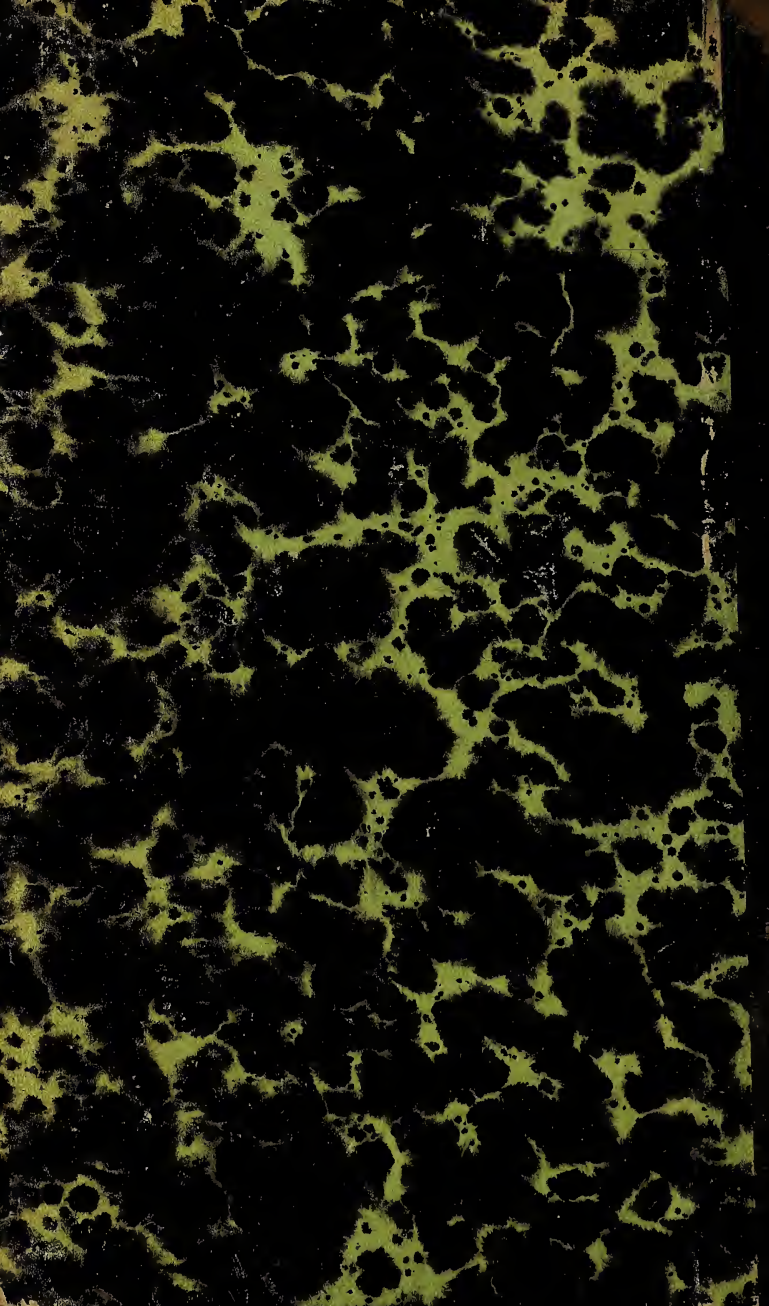

